Marcela Martín del Campo Fierro

\title{
Resposta Pulpar e Periapical de Dentes de Cães após Pulpotomia e Utilização de Derivado da Matriz do ESMALTE. ESTUdo MICROSCóPICO E RADIOGRÁFICO
}

\begin{abstract}
Dissertação apresentada à Faculdade de Odontologia de Ribeirão Preto da Universidade de São Paulo, para obtenção do Título de Mestre em Ciências. Área de concentração: Odontopediatria.
\end{abstract}

Orientador: Prof. Dr. Mário Roberto Leonardo

Ribeirão Preto 
AUTORIZO A REPRODUÇÃO E DIVULGAÇÃO TOTAL OU PARCIAL DESTE TRABALHO, POR QUALQUER MEIO CONVENCIONAL OU ELETRÔNICO, PARA FINS DE ESTUDO E PESQUISA, DESDE QUE CITADA A FONTE.

FICHA CATALOGRÁFICA

Fierro, Marcela Martín del Campo

Resposta pulpar e periapical de dentes de cães após pulpotomia e utilização de Derivado de Matriz do Esmalte. Estudo microscópico e radiográfico. Ribeirão Preto, 2011.

$$
70 \text { p. : il. ; } 30 \mathrm{~cm}
$$

Dissertação de Mestrado, apresentada à Faculdade de Odontologia de Ribeirão Preto/USP - Área de concentração: Odontopediatria.

Orientador: Leonardo, Mário Roberto

Palavras-chave: 1. Pulpotomia 2. Derivado da Matriz do Esmalte 3. Emdogain ${ }^{\circledR} \quad$ 4. Hidróxido de cálcio 5. Óxido de zinco e eugenol 


\section{Resposta Pulpar e Periapical de Dentes de Cães após Pulpotomia e utilização de Derivado da Matriz do ESMALTE. EsTUdo MicroscópICO E RADIOGRÁfICO}

Dissertação apresentada à Faculdade de Odontologia de Ribeirão Preto da Universidade de São Paulo, para obtenção do Título de Mestre em Ciências. Área de concentração: Odontopediatria.

Data da defesa

Banca Examinadora

$\operatorname{Prof}(\mathrm{a}) . \operatorname{Dr}(\mathrm{a})$ :

Instituição:

Julgamento: Assinatura:

$\operatorname{Prof}(\mathrm{a}) \cdot \operatorname{Dr}(\mathrm{a})$ :

Instituição:

Julgamento: Assinatura:

Prof(a).

$\operatorname{Dr}(\mathrm{a})$ : :

Instituição:

Julgamento:

Assinatura: 


\section{Dados CuRriculares}

\section{MarCela Martín del CAMPo FierRo}

Nascimento

Filiação

2002-2007

2008-2011
15 de fevereiro de 1984 - San Luis Potosí, SLP, México

Juan Manuel Martín del Campo Esparza

Margarita Alicia Fierro Muñoz

Curso de Graduação

Facultad de Estomatología

Universidad Autónoma de San Luis Potosí

Curso de Pós-Graduação (Mestrado) em Ciências Área de Concentração: Odontopediatria

Faculdade de Odontologia de Ribeirão Preto / USP 
Fierro, MDCM. Resposta pulpar e periapical de dentes de cães após pulpotomia e utilização de Derivado da Matriz do Esmalte. Estudo microscópico e radiográfico. [dissertação]. Ribeirão Preto (SP): Faculdade de Odontologia de Ribeirão Preto (FORP) - Universidade de São Paulo; 2011.

O objetivo do presente estudo foi avaliar histopatologicamente, a resposta dos tecidos pulpar e periapical de dentes de cães, após pulpotomia e proteção do remanescente pulpar com o Derivado da Matriz do esmalte (Emdogain ${ }^{\circledR}$ ). Foram utilizados 40 dentes (80 raízes), de 4 cães, distribuídos em 6 grupos, nos períodos experimentais de 7 dias (Grupos I, II e II) e 70 dias (Grupos IV, V e VI). Após a remoção da polpa coronária, o remanescente pulpar foi recoberto com os seguintes materiais: Grupo I e IV - Derivado da Matriz do Esmalte (Emdogain ${ }^{\circledR}$ ); Grupos II e V (Controle negativo) - pasta de Hidróxido de Cálcio p.a. e soro fisiológico e Grupos III e VI (Controle positivo) - Óxido de Zinco e Eugenol. Decorridos os períodos experimentais, os animais foram submetidos à eutanásia, as peças removidas e submetidas ao processamento histológico. A avaliação microscópica foi realizada em microscópio óptico com relação à presença ou não da barreira dentinária, severidade da inflamação, presença ou ausência de hemorragia, presença ou ausência de osteogênese focal, presença ou ausência de necrose pulpar, presença de reabsorção radicular externa e espessura do ligamento periodontal. A avaliação radiográfica foi realizada considerando-se a integridade da lâmina dura, presença de áreas de rarefação óssea periapical, de reabsorção radicular (interna e externa) e de ponte de dentina. Os resultados obtidos foram submetidos à análise estatística utilizando-se o teste exato de Fisher $(a=0,05)$. Nos espécimes que apresentavam lesões periapicais, as medidas radiográficas das áreas de rarefação óssea periapical foram comparadas entre grupos por meio do teste de Kruskal-Wallis seguido pelo pós teste de Dunn $(a=0,05)$. Os achados histopatológicos evidenciaram que no período de 7 dias, no Grupo I havia um infiltrado inflamatório leve a moderado e intensa proliferação vascular no tecido pulpar, no Grupo II um infiltrado inflamatório leve, estando o tecido pulpar íntegro enquanto no Grupo III foi observado um infiltrado inflamatório moderado a severo. Em todos os grupos não havia formação de ponte de dentina e a região periapical apresentava aspectos de normalidade. No período de 70 dias, nos Grupos IV e VI não houve formação de ponte de dentina, o tecido pulpar apresentava áreas de necrose com presença de células inflamatórias na região periapical e reabsorção cementária e óssea. Por outro lado, no Grupo V, foi observada a presença de ponte de dentina, ausência de processo inflamatório e ausência de reabsorção dos tecidos mineralizados. Com relação aos achados radiográficos, no período de 7 dias, todos os Grupos (I, II e III) apresentaram integridade da lâmina dura, ausência de rarefação óssea periapical, ausência de reabsorção interna e externa e ausência de formação de ponte dentinária. No período experimental de 70 dias, o Grupo IV apresentou descontinuidade de lâmina dura com presença de rarefação óssea periapical em $100 \%$ dos casos. Ainda, reabsorção radicular interna e formação de ponte dentinária não foram observadas, com reabsorção radicular externa presente em $75 \%$ dos casos. Nos Grupos V e VI, a ausência de integridade da lâmina dura e presença de rarefação periapical foram observadas em $25 \%$ e $50 \%$ dos casos, respectivamente, e reabsorção radicular externa em $25 \%$ dos casos. Reabsorção radicular interna e formação de ponte dentinária não foram observadas em nenhum dos grupos. Os resultados microscópicos e radiográficos permitiram concluir que o Derivado da Matriz do Esmalte $\left(\right.$ Emdogain $^{\circledR}$ ) não apresentou resultados satisfatórios quando aplicado sobre o tecido pulpar exposto na técnica da pulpotomia.

Palavras-chave: Pulpotomia, Derivado da Matriz do Esmalte, Emdogain ${ }^{\circledR}$, Hidróxido de Cálcio, Óxido de Zinco e Eugenol. 
Fierro, MDCM. Pulpal and periapical response of dogs' teeth after pulpotomy and use of Enamel Matrix Derivative. Histopatologic and radiographic study. [dissertation]. Ribeirão Preto (SP): Faculdade de Odontologia de Ribeirão Preto (FORP) - Universidade de São Paulo; 2011.

The purpose of this study was to evaluate, both histopatologically and radiographically, the pulpal and periapical response of dogs' teeth after pulpotomy and use of Enamel Matrix Derivative (Emdogain ${ }^{\circledR}$ ). For such purpose, 40 teeth (80 roots), obtained from 4 dogs, were assigned to 6 groups and evaluated in two experimental periods: 7 days (Groups I, II, and III) and 70 days (Groups IV, V and, VI). After pulpotomy, pulp remnant was covered with the following materials: Groups I and IV - Enamel Matrix Derivative (Emdogain ${ }^{\circledR}$ ); Groups II and V (negative control) - Calcium hydroxide p.a.; and Groups III and VI (positive control) - Zinc oxide and eugenol. At the established experimental periods, the animals were euthanized and the anatomic pieces were obtained and histologically processed. The microscopic evaluation was performed in a light microscope regarding the presence or absence of induced dentin barrier, severity of inflammation, presence or absence of bleeding, presence or absence of focal osteogenesis, presence or absence of pulp necrosis, presence of external root resorption and periodontal ligament thickness. Radiographic evaluation was performed considering the integrity of the lamina dura, presence of areas of periapical bone rarefaction, root resorption (internal and external) and dentin bridge formation. The results were analyzed statistically using Fisher's exact test $(a=0.05)$. In the specimens presenting apical periodontitis, the areas of the lesions were determined and the groups were compared using the Kruskal-Wallis test followed by Dunn test $(a=0.05)$. The histopathologic findings in the 7-day period revealed that Group I presented a mild to moderated inflammatory infiltrate and intense vascular proliferation in the pulp tissue; Group II presented a mild inflammatory and an intact pulp tissue, while Group III presented a moderate to severe inflammatory infiltrate. In all groups, there was no dentin bridge formation and the periapical region had normal appearance. In the 70-day period, Groups IV and VI showed no dentin bridge formation and pulp tissue presented necrotic areas with inflammatory cells in the periapical region as well as bone and cemental resorption. On the other hand, in Group V, there was dentin bridge formation, absence of inflammatory process and absence of resorption of mineralized tissues. Regarding the radiographic findings, in the 7-day period, all specimens in Groups I, II e II present intact lamina dura, absence of periapical bone rarefaction, absence of root resorption (internal and external) and absence of dentin bridge formation. In the experimental 70-day period, Group IV showed discontinuity of the lamina dura and presence of periapical bone rarefaction in $100 \%$ of cases. Internal root resorption and dentin bridge formation were not observed, with external root resorption in $75 \%$ of cases. In Groups V and VI, absence of hard layer and presence of periapical bone rarefaction were observed in $25 \%$ and $50 \%$ of cases, respectively and external root resorption in $25 \%$ of cases. Presences of internal root resorption and dentin bridge formation were not observed in any group. Based on these results, it may be concluded that Enamel Matrix Derivative (Emdogain ${ }^{\circledR}$ ) did not present satisfactory results when applied on the pulp tissue following pulpotomy.

Key words: Pulpotomy, Enamel Matrix Derivative, Emdogain ${ }^{\circledR}$, Calcium Hydroxide, Zinc Oxide and Eugenol. 


\section{SUMÁRIO}

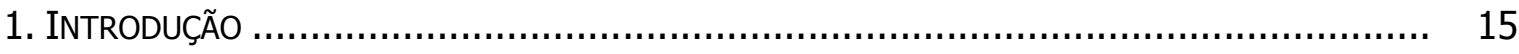

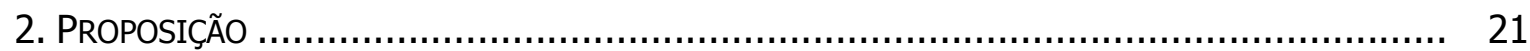

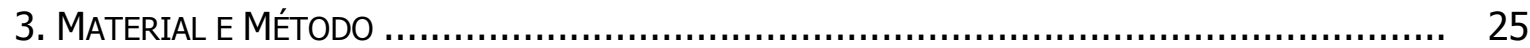

3.1 PROCEDIMENTOS OPERATÓRIOS........................................................... 28

3.2 PROCESSAMENTO HISTOLÓGICO......................................................... 30

3.3 ANÁLISE MICROSCÓPICA .............................................................. 31

3.4 AVALIAÇÃO RADIOGRÁFICA .............................................................. 32

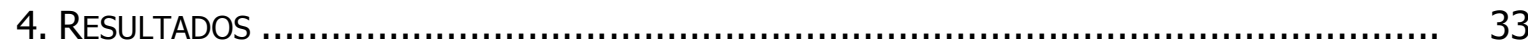

4.1 RESULTADOS MICROSCÓPICOS........................................................ 35

4.2 RESULTADOS RADIOGRÁFICOS......................................................... 45

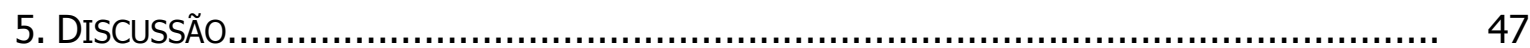

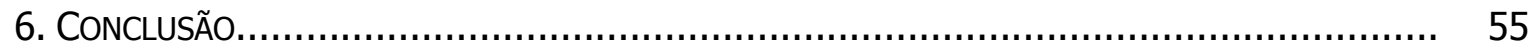

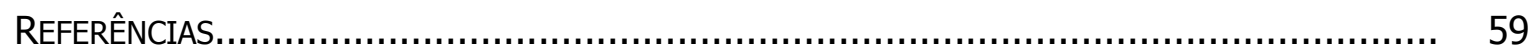

ANEXO 
$\mathcal{A}$ Deus por ter traçado o caminho da minha vida e permitir que o percorresse cheio de pessoas e experiências inesqueciveis, tropeços e ensinamentos. Por ter me dado uma vída cheía de luz e amor. Pela oportunidade de ser quem eu sou, estar aqui, e aprender coisas novas todos os dias.

À os dois grandes pilares da minha vida: meus país Juan Manuel Martín del Campo Esparza e Margarita Alicía Fierro Muñoz. Pelo apoio, os ensinamentos e o exemplo de papai, e pelo incentivo, dedicação e amizade de mamãe (sem você não tería conseguido, estarei agradecida além do tempo). $\mathcal{E}$ ainda mais pela fé que depositaram em mím. Por serem estas pessoas que me fazem ir sempre para frente. Este esforço e esta conquista são seus também. Simplesmente eu os amo.

Aos meus 3 anjos...

Juan Manuel: Por me ensinar que a vida tem um lado divertido e positivo. Por demonstrar esse carinho e responsabilidade de irmão mais velho. Você é exemplo de alegria e disposição para todas as pessoas. $\mathcal{A}$ fé, confiança e o amor que você tem em mim são sempre mais do que eu podería esperar. Te amo Manu!

Luis: por ser um exemplo de pessoa (não somente para mim, mas para muita gente também, pelo incentivo pra me colocar metas altas e por me ajudar a consegui-las. Por me fazer ver que os sonhos não são inalcançáveis e que com trabalho e dedicação os objetivos sempre podem ser cumpridos. Te quiero Pollo.

Carlos: Por ser uma pessoa especial neste mundo, por me lembrar que Deus esta conosco sempre e que nos ama. Por ser meu amigo e colega em muitas etapas da minha vida. A fé e o carinho que você deposita em mim me fazem querer ser uma pessoa melhor a cada dia. Gracias Mico. 
Ao meu Orientador Prof. Dr. Márío Roberto Leonardo, exemplo de dedicação e amor à profissão. Meu agradecimento pelos ensinamentos fumildade e simpatía.

À Profa. Dra. Léa Assed Bezerra da Sílva, pela oportunidade de realizar o curso do Mestrado na Faculdade de Odontología de Ribeirão Preto, da Universidade de São Paulo. Obrigada por acreditar em mim, pelo incentivo constante, pelos ensinamentos dentro e fora da faculdade, e por me acolher como parte de sua familia. 
Ao Francísco Wanderley García de Paula e Sílva pela disposição, pelo apoio, pela paciêncía, pelos ensinamentos e pela valiosa colaboração na execução deste trabalho.

À Familia Martín del Campo e Familia Fierro. Primeiramente duas pessoas maravilhosas, minhas avós (Julita e Carmenchú), exemplos de atitude positiva e amor pelo trabalho e pela familia. À todos meus tíos, primos e sobrinhos. Cada um de vocês faz parte do meu coração e meus pensamentos. São peças importantes da minha vida, sei que sempre acreditaram em mim, por isso e pelo seu carinho é que eu posso alcançar minhas metas. Amo todos vocês.

À Família Sílva Herzog, por ter acreditado em mim, pelos incentivos, e o carinho que recebi sempre de sua parte, por me deixar sentir que formava parte de sua familia, o que fez mais fácil este processo. Pela oportunidade e ajuda para realizar este sonho. Ao Dr. Daniel exemplo de dedicação, paciência e amor à profissão. $\mathcal{A}$ Elvíra pelas palavras, pelos conselhos e pelos bons momentos.

À Profa. Dra. Raquel Assed Bezerra da Sílva, minha amiguita. Obrigada pela confiança, por acreditar em mim, pelos incentivos que me ajudam a crescer e melhorar em muitos aspetos da minha vida, por abrir as portas do teu coração e da tua família, por ser um exemplo de mulher, uma amiga incondicional e uma excelente pessoa.

$\mathcal{A}$ minha amiga Daniella Sílva-Herzog Rivera, por ter acreditado em mim, porque sem tua ajuda e da tua familia nada disto tería se tornado realidade. Por ser a pessoa que me acompanhou numa etapa inesquecivel da vida, por todos os momentos e experiências que vivemos juntas, por me ensinar que a vida sempre tem um lado divertído o que tornou este processo em algo muito agradável. Você forma e formará parte da minha vída sempre. 
Ao Prof. Dr. Alberto Consolaro exemplo de ser humano e mestre. Obrigado pelos seus ensinamentos, pela alegre convivêncía e pela colaboração valiosa para meu aprendizado.

Ao Prof. Dr. Paulo Nelsson-Fílho, pelo estímulo, dedicação e paciência ao transmitir seus conhecimentos e experiências, pela disposição que tem sempre para todos seus alunos e pela simpatia e alegria que transformaram o trabalho em bons momentos.

À Profa. Dra. Alexandra Mussolino de Queíroz, pela forma atenciosa e carinhosa que teve para comigo desde o momento em que me conheceu, pela alegría, otimismo e dedicação, pela sua amizade, as conversas agradáveís e os momentos gratos. Obrigada Danda.

À Profa. Dra. Kranya Víctóría Díaz Serrano, pela agradável convivência, por ser essa pessoa sempre disponivel, pelo incentivo e o apoío. Professores como você facílitaram minha estadia no Brasil e tornaram mais fácil este processo.

À Profa. Dra. María Crístina Borsatto, pela sua disponibilidade, simpatia e alegria, por ser um exemplo de dedicação, amabilidade, humildade e amor ao próximo.

À Profa. Dra. Aldevina Campos de Freitas, por ser um exemplo de amor e dedicação à profissão, pela paciência, disposição e humildade ao transmitir seus conhecimentos.

À Profa. Dra. Sada Assed, por ser um exemplo de determinação, dedicação e amor à profissão.

Às minhas inesqueciveis amigas e companheiras de casa: Ana Paula Zanetti Brochini, Maria Elisa Castela e Talitha de Síqueira Mellara, pela ajuda, amizade, confiança, risadas, experiências, conversas e momentos agradáveis. Por serem parte muito importante da minha vida, por abrirem seus corações $e$ facilitarem minha estadia no Brasil. Por terem me acolhido e terem sido as minhas irmãs. Estarei eternamente agradecida. 
À minhas amigas: Milly, Clavos, Andre, Any, Kîkis, Flore, Steph, Pupe, pelos cafés, as conversas, a confíança, motivação, apoio e a amizade durante todos estes anos.

ג̇ Faculdade de Odontologia de Ribeirão Preto da Universidade de São Paulo, na pessoa do atual diretor Prof. Dr. Osvaldo Luíz Bezzon e do Více-Díretor Prof. Dr. Valdemar Mallet da Rocha Barros.

À Coordenação do Curso de Pós-Graduação em Odontopediatría da Faculdade de Odontologia de Ribeirão Preto da Universidade de São Paulo, na pessoa da Coordenadora Profa. Dra. Léa Assed Bezerra da Sílva e do Více-Coordenador Prof. Dr. Paulo NelsonFílho.

Aos Professores do Departamento de Clinica Infantil, Odontología Preventiva e Social da Faculdade de Odontología de Ribeirão Preto da Universidade de São Paulo, Profa. Dra. Sada Assed, Prof. Dra. Léa Assed Bezerra da Sílva, Profa. Dra. Aldevina Campos de Freitas, Prof. Dr. Paulo Nelson-Filho, Profa. Dra. $\mathcal{A}$ lexandra Mussolino de Queiroz, Prof. Dr. Márío Roberto Leonardo, Profa. Dra. Raquel Assed Bezerra da Sílva, Profa. Dra. Kranya Víctória Díaz Serrano, Profa. Dra. María Crístina Borsatto, Profa. Dra. Mirian Aiko Nakane Matsumoto, Prof. Dr. José Tracísio Líma Ferreíra, Prof. Dr. Adilson Thomazinho, Profa. Dra. María Bernadete Sasso Stuani, Profa. Dra. María Conceição Pereira Saravía, Prof. Dr. Fábío Lourenço Romano e Profa. Dra. Andiara De Rossí.

Aos meus amigos e colegas da Pós-Graduação Camíla Scatena, Cíntía Guimarães de Almeída, Danielle Torres Azevedo, Luciane Almeida do Carmo, Marilia Pacífico Lucísano, Paula Dariana Fernandes Ferreira, Rodrigo Alexandre Valério, Talitha de Siqueira Mellara, Elaine Machado Pingueiro, Fernanda Regina Ribeiro Santos, Iliana Ferraz Sabbatini, Késsia Suênia Fidelis de Mesquita, Lígía María Napolitano Gonçalves, Cristiane Tomaz Rocha, Fabrícío Kítazono de Carvalho, por tornarem mais fácil e agradável este processo, pelos momentos compartilhados, a amizade e a convivêncía. 
Aos funcionários do Departamento de Clinica Infantil, Odontología Preventiva e Social da Faculdade de Odontologia de Ribeirao Preto da Universidade de São Paulo, Mícheli Crístina Leite Rovanholo, Fílomena Leli Placcití, Francísco Wanderley García de Paula e Sílva, Carolina Paes Torres Mantovani, JMarco Antonio dos Santos, Nilza Letícía Magalhães, Fátima aparecida Rizoli, Fátíma Aparecída Jacínto Daniel, Renata Aparecída Fernandes e Matheus Morelli Zanela, pela sua ajuda, paciência e amizade.

À Fundação de Amparo à Pesquísa do Estado de São Paulo e à Coordenação de Aperfeiçoamento de Pessoal de $\mathcal{N} i v$ el Superior, pelo suporte científico e financeiro fundamentais para a realização deste trabalho. 
INTRODUÇÃO 



\section{INTRODUÇÃO}

O Derivado da Matriz do Esmalte (EMD) é composto por um grupo de proteínas, principalmente amelogeninas, originárias da bainha epitelial de Hertwig de suínos, empregado com sucesso no auxílio de processos de regeneração periodontal (Hammarström et al., 1997; Sculean et al., 2001; Venezia et al., 2004; Rodrigues et al., 2007; Lossdöfer et al., 2007; Sculean et al., 2007). Essas proteínas são conhecidas por desempenharem um importante papel na cementogênese e no desenvolvimento da inserção periodontal (Ten Cate, 1996; Hammarström, 1997), estando a amelogenina e a enamelina envolvidas no estágio final de diferenciação de odontoblastos, com subsequente deposição de dentina durante a dentinogênese (Inai et al., 1991; Spahr et al., 2002; Papagerakis et al., 2003).

Em nível celular, o EMD estimula a proliferação de fibroblastos, aumenta a síntese de proteínas e de colágeno, promove a formação de nódulos mineralizados por células do ligamento periodontal (Gestrelius et al., 1997; Palioto et al., 2004; Rodrigues et al., 2007) e aumenta as taxas de expressão de fatores de crescimento (TGF-a, TGF- $\beta$ e IL-6, entre outros) e o metabolismo dos fibroblastos do ligamento periodontal (Lyngstadaas et al., 2001), sem estimular células epiteliais (Hoang et al., 2000; Cattaneo et al., 2003).

O EMD estimula também a angiogênese, possivelmente atuando nas células endoteliais e elevando a produção de fatores angiogênicos (VEGF) por células do ligamento periodontal. Assim, o EMD aumenta a comunicação bidirecional entre as células endoteliais microvasculares humanas e as células do ligamento periodontal, durante a angiogênese associada ao reparo (Schlueter et al., 2007). Além disso, o EMD promove diferenciação das células do ligamento periodontal e produção de osteoprotegerina, resultando também em um microambiente favorável à ocorrência do processo de reparo (Lossdöfer et al., 2007).

Dentre os efeitos do EMD pode-se destacar, também, o estímulo à proliferação de osteoblastos e à diferenciação em células ósseas maduras (Schwartz et al. 2000; Jiang et al., 2001; He et al., 2004), inibição da apoptose de osteoblastos, aumento da capacidade osteogênica das células da medula óssea (Keila et al., 2004; He et al., 2005), inibição da expressão dos genes envolvidos nas fases inflamatórias precoces e estímulo à expressão dos genes envolvidos no crescimento e no reparo (Parkar e 
Tonetti, 2004). Têm-se observado que o EMD induz a diferenciação de células derivadas da medula óssea em cementoblastos (Song et al., 2007).

Em 2007, Narani et al. salientaram que o EMD se adere às proteínas da matriz extracelular de feridas e regula suas propriedades adesivas. Essas interações podem favorecer a adesão de fibroblastos sobre as células epiteliais, potencializando a regeneração do tecido conjuntivo.

O Emdogain ${ }^{\circledR}$ (Biora AB, Malmö, Suécia) é um gel que consiste de um derivado da matriz do esmalte (EMD) em um veículo de alginato de propilenoglicol (PGA), aplicado na área da Periodontia para obter a regeneração biológica da perda de inserção dental por promover a migração, a proliferação e a diferenciação de fibroblastos do ligamento periodontal, cobrindo a superfície radicular exposta (Heijl et al., 1997; Rasperini et al., 1999). Essa formulação contém um extrato de proteínas da matriz do esmalte de baixo peso molecular, com predominância da amelogenina, onde o EMD é tratado por meio do calor o que, juntamente com o PGA, reduz os riscos de contaminação microbiana (Bratthall et al., 2001; Nagano et al., 2004).

Avaliações clínicas têm evidenciado que o uso do EMD (Emdogain $\left.{ }^{\circledR}\right)$, durante o tratamento periodontal, resulta na regeneração do cemento, recuperação significante de inserção e reparação óssea (Hammarström, 1997; Heijl et al., 1997; Mellonig, 1999; Aimetti et al., 2007; Sculean et al., 2007; Saito et al., 2010). Recentemente, o Emdogain ${ }^{\circledR}$ foi avaliado em 8 trabalhos publicados na área da Endodontia, com relação à capacidade de formação de dentina de reparação, após proteção pulpar direta em dentes de porcos-miniatura (Nakamura et al., 2001), dentes de cães (Ishizaki et al., 2003), molares de ratos (Igarashi et al., 2003), dentes de humanos (Olsson et al., 2005; Kiatwateeratana et al., 2009; Fransson et al., 2010), e após pulpotomia em dentes de porcos-miniatura (Nakamura et al., 2002; Nakamura et al., 2004).

Os resultados com relação à capacidade do Derivado da Matriz do Esmalte induzir a deposição de dentina de reparação são divergentes. Alguns autores observaram que o EMD induziu a deposição de um tecido neoformado semelhante à dentina ("dentin-like") (Nakamura et al., 2001; Nakamura et al., 2002; Ishizaki et al., 2003; Olsson et al., 2005), possivelmente por mimetizar os mediadores biológicos que estão normalmente ativos durante os estágios precoces da dentinogênese, com diferenciação de odontoblastos (Nakamura et al., 2001). O Emdogain ${ }^{\circledR}$ estimula a proliferação de odontoblastos e de osteoblastos in vitro, sem a necessidade de contato direto com o material (Jiang et al., 2006). Por outro lado, outros autores 
demonstraram que a capacidade de formar uma barreira estrutural para proteção da polpa é improvável, uma vez que o EMD é capaz apenas de induzir a formação de ilhotas de tecido mineralizado desorganizado (Kiatwateeratana et al., 2009; Fransson et al., 2010). O Emdogain ${ }^{\circledR}$ é um material de consistência gelatinosa e sua solubilização leva à proliferação do tecido pulpar em direção coronária, no sentido de ocupar o espaço deste material (Olsson et al., 2005).

Pelo exposto verifica-se que, embora o Derivado da Matriz do Esmalte $\left(\right.$ Emdogain ${ }^{\circledR}$ ) venha sendo amplamente estudado na área da Periodontia, poucos estudos têm sido direcionados à avaliação do uso desse material nas terapias conservadoras do tecido pulpar. 



\section{ProposiçÃo}





\section{ProposiçÃo}

Em função da escassez de estudos enfocando a reação do tecido pulpar frente ao emprego do Derivado da Matriz do Esmalte (EMD), o objetivo do presente estudo foi avaliar microscopica e radiograficamente, a resposta dos tecidos pulpar e periapical de dentes de cães, após pulpotomia e proteção do remanescente pulpar com Emdogain $^{\circledR}$. 

Material e Método 



\section{Material e MÉtodo}

O presente estudo foi realizado de acordo com as normas da International Organization for Standardization (ISO) no 7405:2008. Após aprovação do projeto de Pesquisa pela Comissão de Ética no Uso de Animais da Universidade de São Paulo Campus de Ribeirão Preto, processo número 2008.1.87.53.9, foram selecionados os $2^{\text {os }}$ e $3^{\text {os }}$ pré-molares superiores e os $2^{\text {os }}, 3^{\text {os }}$ e $4^{\text {os }}$ pré-molares inferiores de 4 cães, provenientes de uma mesma ninhada, sem raça definida, de ambos os gêneros, com 12 meses de idade e pesando, em média, 15 quilos. Deste modo, foram utilizados 40 dentes (80 raízes), distribuídos em 6 grupos, conforme descrito na Tabela 1.

Tabela 1 - Material utilizado no presente estudo, distribuição do número de dentes para cada grupo e períodos experimentais

\begin{tabular}{clcc}
\hline Grupo & \multicolumn{1}{c}{ Material } & Número de dentes & $\begin{array}{c}\text { Período } \\
\text { Experimental }\end{array}$ \\
\hline I & Emdogain $^{\circledR}$ & 12 dentes (24 raízes) & 7 dias \\
II & Hidróxido de Cálcio (Controle Negativo) & 4 dentes ( 8 raízes) & 7 dias \\
III & Óxido de Zinco e Eugenol (Controle Positivo) & 4 dentes (8 raízes) & 7 dias \\
IV & Emdogain ${ }^{\circledR}$ & 12 dentes (24 raízes) & 70 dias \\
V & Hidróxido de Cálcio (Controle Negativo) & 4 dentes (8 raízes) & 70 dias \\
VI & Óxido de Zinco e Eugenol (Controle Positivo) & 4 dentes (8 raízes) & 70 dias \\
\hline
\end{tabular}

Os animais receberam vermífugos (Drontal ${ }^{\circledR}$ Puppy - Bayer - São Paulo Brasil) (1 comprimido a cada $10 \mathrm{~kg}$ de peso do animal) e vitaminas (Glicopan ${ }^{\circledR}$ Pet Vetnil Indústria e Comércio de Produtos Veterinários Ltda - Louveira - Brasil) e foram aplicadas vacinas anti-rábica (Rai-Vac $I \circledast$ - Fort Dodge - Campinas - Brasil) e Duramune (Fort Dodge - Campinas - Brasil), em 3 doses, com 3 semanas de intervalo entre cada aplicação. Os cães foram mantidos no Biotério da Faculdade de Odontologia de Ribeirão Preto da Universidade de São Paulo, com livre acesso à água e dieta padrão da Unidade durante todo o período de experimentação.

\section{Anestesia inalatória}

Inicialmente os animais foram pré-anestesiados, por meio de injeção por via endovenosa de $1 \mathrm{mg} / \mathrm{kg}$ de peso de Neozine (Aventis Pharma Ltda, Souzano, SP Brasil), 15 minutos antes do ato operatório. Em seguida, foi aplicado Zoletil ${ }^{\circledR} 50$ (Virbac do Brasil, São Paulo, SP - Brasil), na dosagem de $0,1 \mathrm{ml} / \mathrm{kg}$ de peso, por via 
endovenosa, para facilitar a passagem da sonda endotraqueal, necessária para a realização da anestesia inalatória.

Após a intubação com sonda endotraqueal, a manutenção da anestesia foi realizada com Isoflurano (Abbott Laborat. Do Brasil Ltda. - Rio de Janeiro - Brasil), utilizando o aparelho para anestesia inalatória Takaoka KT-20 (São Paulo - Brasil). Durante todo ato operatório, os animais foram mantidos com solução isotônica de cloreto de sódio a 0,9\% (Glicolabor Indústria Farmacêutica Ltda. - Ribeirão Preto Brasil).

\subsection{Procedimentos operatórios}

A seguir, foi efetuado o exame radiográfico periapical dos dentes utilizados no estudo, utilizando um dispositivo para padronização de tomadas radiográficas em cães

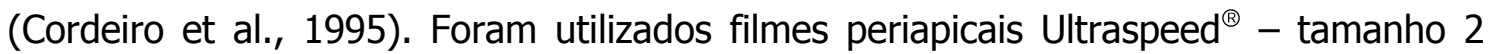
(Eastman Kodak Company - Rochester - EUA), aparelho de raios-X odontológico Heliodent ${ }^{\circledR}$ (Siemens - New York - EUA), com 60 kVp e 10 mA e tempo de exposição de 1 segundo. As radiografias foram reveladas pelo método tempo / temperatura e arquivadas em cartelas plásticas.

Todo o instrumental utilizado nos procedimentos operatórios foi esterilizado em autoclave a $121^{\circ} \mathrm{C}$, por 20 minutos (Souza-Gugelmin et al., 2005). A profilaxia dental foi realizada com o objetivo de remover cálculo e biofilme, seguida pela anestesia infiltrativa complementar com Mepivacaína a 2\% com Noradrenalina 1:100.000 (Scandicaine $^{\circledR}$ - Septodont Distribuidora DFL Indústria e Comércio Ltda - Rio de Janeiro - Brasil).

A seguir, foi realizado o isolamento do campo operatório com dique de borracha, e anti-sepsia com peróxido de hidrogênio a $3 \%$, seguida pela aplicação de digluconato de clorexidina a 2,0\%. A abertura coronária foi realizada utilizando pontas esféricas diamantadas número 1015 (K.G. Sorensen - São Paulo - Brasil) montadas em caneta de alta rotação, refrigeradas a ar e água, determinando uma cavidade classe I, na qual foi removida a ponte de esmalte, de maneira a unir a embocadura dos canais radiculares mesial e distal (Silva, 2006). A cada 4 preparos cavitários uma nova ponta diamantada foi utilizada para assegurar a eficiência de corte e evitar o aquecimento excessivo.

A câmara pulpar foi então irrigada com solução de soro fisiológico esterilizado (Glicolabor Indústria Farmacêutica Ltda. - Ribeirão Preto - Brasil) e realizada a 
amputação da polpa coronária, com curetas endodônticas afiadas, até o nível da entrada dos canais radiculares. A hemostasia foi obtida por meio de irrigação da câmara pulpar com solução de soro fisiológico.

Para que todas as variáveis fossem testadas em um mesmo animal, e em diferentes quadrantes, cada hemi-arco recebeu, em sistema de rodízio distribuído ao acaso, os diferentes produtos avaliados, sendo seguidas as instruções dos fabricantes.

- Grupos I (7 dias) e IV (70 dias): nesses grupos foi avaliado o Derivado da Matriz do Esmalte (Emdogain ${ }^{\circledR}$ - Biora $A B$ - Malmö - Suécia), disponível sob a forma de gel, contendo $30 \mathrm{mg} / \mathrm{ml}$ de EMD em alginato de propilenoglicol (PGA). O gel foi colocado com seringa sobre o tecido pulpar. Em seguida, o material foi recoberto com um disco de guta-percha e as margens foram vedadas com cera.

- Grupos II (7 dias) e V (70 dias): nesses grupos foi avaliada a pasta de hidróxido de cálcio p.a. (Calcium Hidroxide zur Analyse - Merck - Darmstadt Alemanha). $O$ pó de hidróxido de cálcio $(0,5 \mathrm{~g})$ foi manipulado com soro fisiológico $(0,5$ $\mathrm{mL}$ ) em uma placa de vidro esterilizada até a obtenção de uma pasta espessa, a qual foi colocada sobre todo o tecido pulpar com o auxílio de uma cureta e acomodada com mechas de algodão esterilizadas, sem pressão excessiva.

- Grupos III (7 dias) e VI (70 dias): nesses grupos foi avaliado o óxido de zinco e eugenol $\left(\right.$ IRM $^{\circledR}$ - Dentsply Indústria e Comércio Ltda. - Petrópolis - Brasil). 0 pó de óxido de zinco ( $1 \mathrm{~g}$ ) foi manipulado com eugenol (1 gota) em uma placa de vidro esterilizada, a qual foi colocada sobre o tecido pulpar com o auxílio de uma cureta e acomodada com mechas de algodão esterilizadas, sem pressão excessiva.

Em todos os grupos o material protetor foi recoberto com cimento de hidróxido de cálcio (Dycal ${ }^{\circledR}$ - Dentsply Indústria e Comércio Ltda. - Petrópolis - Brasil) e a cavidade restaurada com amálgama de prata (Velvalloy - S.S. White Artigos Dentários Ltda. - Rio de Janeiro - RJ), manipulado de acordo com as instruções do fabricante. Após o término dos procedimentos operatórios foi efetuado o exame radiográfico e a aplicação de analgésico (Cloridrato de Tramadol, Medley S/A - Campinas - Brasil), na dosagem de $3 \mathrm{mg} / \mathrm{kg}$ de peso, por via endovenosa, a cada 12 horas, durante 2 dias.

Os animais foram acompanhados durante todo o período experimental para observação de mudanças de hábitos alimentares, desenvolvimento de processos inflamatórios ou supuração dos tecidos, dentre outras anormalidades.

Decorridos os períodos experimentais de 7 (Grupos I, II e III) e 70 dias (Grupos 
IV, $\mathrm{V}$ e VI), as hemi-arcadas foram radiografadas, da mesma maneira descrita anteriormente, e os animais foram submetidos à eutanásia. Inicialmente os animais foram submetidos a tranquilização com Neozine (Aventis) injetável, na dosagem de 1 $\mathrm{mg} / \mathrm{kg}$ de peso. Após 15 minutos, foi efetuada a anestesia com Thiopental (Thionembutal - Abbot Laboratórios do Brasil, Ltda. - Rio de Janeiro - RJ) endovenoso, na dosagem de $25 \mathrm{mg} / \mathrm{kg}$ de peso, injetado lentamente. Em seguida, foi efetuada a eutanásia com cloreto de potássio a 20\%, endovenoso, na dosagem de $100 \mathrm{mg} / \mathrm{kg}$ de peso, injetado lentamente.

As maxilas e mandíbulas foram dissecadas, com auxílio de um bisturi, reduzidas em seu volume e as peças lavadas em água corrente. Para facilitar o processamento histológico, as peças foram seccionadas utilizando discos diamantados, sob constante refrigeração com água, sendo obtidos blocos das peças anatômicas contendo os dentes individualmente.

\subsection{Processamento histológico}

As peças foram submetidas à fixação em solução de formol tamponado a $10 \%$, por 72 horas, à temperatura ambiente. Posteriormente, as peças foram imersas em um recipiente de vidro contendo uma solução à base de ácido etilenodiaminotetracético (EDTA Disodium Salt Dihydrate - Merck - Darmstadt Alemanha) a 10\% e submetidas à desmineralização, acelerada pelo forno microondas (Sharp Carousel ${ }^{\circledR}$ - São Paulo Brasil). Para a realização deste procedimento, o recipiente contendo as peças foi parcialmente imerso em outro recipiente de vidro contendo água e gelo, com o objetivo de retardar o aumento da temperatura e, consequentemente, incrementar o tempo de ação das microondas. O forno de microondas operou na frequência de trabalho de $2450 \mathrm{MHz}$, correspondendo a uma frequência de onda no vácuo de $12,2 \mathrm{~cm}$, potência máxima nominal de $700 \mathrm{~W}$, regulado em potência média / máxima à temperatura de $30^{\circ} \mathrm{C}$ para evitar alterações teciduais. As peças foram irradiadas por 10 minutos, com intervalos de 5 minutos entre as irradiações, por um período de 4 horas / dia. No intervalo entre os dias, o material permaneceu na solução desmineralizadora sem agitação, à temperatura ambiente.

A completa desmineralização das amostras, avaliada por meio da penetração de uma agulha nos tecidos para verificação da sua consistência e por meio de exame radiográfico das peças, foi obtida em aproximadamente 30 dias. Concluída a desmineralização, as peças foram neutralizadas em solução de sulfato de sódio a 5\% (Sulfato de Sódio Anhido - J.T.Baker - Xalostoc - México) por 24 horas, lavadas em água corrente por 24 horas, desidratadas em concentrações crescentes de álcool (Álcohol Etílico Absoluto Anhidro ${ }^{\circledR}$ - J.T. Baker), diafanizadas em xilol (Xylol ${ }^{\circledR}$ - Merck) e incluídas em parafina (Histosec ${ }^{\circledR}$ Pastillen - Merck), de acordo com a rotina 
histotécnica. Os blocos contendo os dentes individualizados foram reduzidos pela microtomia a cortes seriados longitudinais com 5,0 $\mu \mathrm{m}$ de espessura. Para avaliação microscópica, as lâminas foram coradas pela Hematoxilina e Eosina (HE), Tricrômico de Mallory e pelo método de Brown \& Brenn e observadas em microscópio óptico.

\subsection{Análise microscópica}

A análise microscópica foi realizada por microscopia óptica, sem conhecimento prévio do espécime. Os parâmetros histomorfológicos empregados no presente estudo (Tabela 2) foram baseados em critérios descritos previamente (Holland et al., 2005; Albuquerque et al., 2006; Leonardo et al., 2007). Durante a análise das lâminas foram atribuídos escores a cada parâmetro. Os resultados obtidos foram submetidos à análise estatística por meio dos testes de Kruskal-Wallis seguido pelo pós-teste de Dunn ou pelo teste de Mann-Whitney, com nível de significância de 5\% utilizando o Software Graph Pad Prism 5.0 (San Diego - EUA).

Tabela 2 - Parâmetros e escores empregados para avaliação microscópica no tecido pulpar, no local da exposição e nos tecidos apicais e periapicais.

\begin{tabular}{ll}
\hline Parâmetros & Escores \\
\hline Espessura da barreira dentinária & Escore 0: ausente \\
& Escore 1: fina \\
& Escore 2: média \\
& Escore 3: muito espessa \\
\hline Severidade da reação inflamatória & Escore 0: ausente \\
& Escore 1: leve \\
& Escore 2: moderada \\
& Escore 3: severa \\
\hline Hemorragia & Escore 0: ausente \\
& Escore 1: presente \\
\hline Osteogênese focal & Escore 0: ausente \\
& Escore 1: presente \\
\hline Necrose pulpar & Escore 0: ausente \\
& Escore 1: presente \\
\hline Reabsorção radicular externa & Escore 0: ausente \\
& Escore 1: presente \\
\hline Espessura do ligamento periodontal & Escore 0: normal \\
& Escore 1: suavemente aumentado \\
& Escore 2: moderadamente aumentado \\
& Escore 3: severamente aumentado \\
\hline
\end{tabular}




\subsection{Avaliação radiográfica}

A avaliação radiográfica foi realizada utilizando as radiografias periapicais obtidas previamente à execução dos atos operatórios e após 7 dias e 70 dias da intervenção. As radiografias foram avaliadas com relação à presença ou ausência da lâmina dura, de áreas de rarefação óssea periapical, de reabsorções radiculares (interna e externa) e de ponte de dentina. A concordância entre os examinadores foi determinada pelo teste kappa. Os resultados obtidos foram submetidos à análise estatística por meio do teste Exato de Fisher, com nível de significância de 5\%.

Os grupos I, II e III foram comparados entre si no período de 7 dias e os grupos IV, V e VI foram comparados entre si no período de 70 dias. Com o objetivo de avaliar se havia diferença nos resultados radiográficos entre os dois períodos experimentais, os grupos I, II e III no período de 7 dias foram comparados respectivamente com os grupos IV, V e VI no período de 70 dias.

Para mensuração das lesões periapicais, quando presentes, as radiografias das hemi-arcadas, obtidas previamente à morte dos animais, foram digitalizadas com auxílio de scanner óptico (Hewlett-Packard - Scanjet 7450 c series - programa versão 3.0.2 - San Diego - EUA) e transferidas para o programa Image J 1.37u (National Institutes of Health - Betheseda - EUA), como descrito previamente (Silva et al., 2008). Com o objetivo de calibrar o programa foi realizada a medida da distância da face mesial à face distal de cada dente, com compasso de ponta seca, sendo esta medida transferida para o programa. A delimitação e a medida da área radiolúcida sugestiva de lesão periapical, presente em cada raiz, foi determinada em $\mathrm{mm}^{2}$. Para a realização da análise estatística com relação às medidas das áreas de rarefação óssea periapical sugestivas de lesão periapical foi utilizado o teste não-paramétrico de Kruskal-Wallis seguido pelo pós-teste de Dunn, com nível de significância de 5\%. 
Resultados 



\section{Resultados}

\subsection{Resultados microscópicos}

Os resultados da análise microscópica foram descritos com respeito à espessura da barreira dentinária, severidade da inflamação, presença ou ausência de hemorragia, presença ou ausência de osteogênese focal, presença ou ausência de necrose pulpar (Quadro 1), presença ou ausência de reabsorção radicular externa e espessura do ligamento periodontal (Quadro 2). Durante o processamento histológico foram perdidos 1 espécime do Grupo V e 1 espécime do Grupo VI.

\section{Emdogain $^{\circledR}$}

\section{7 dias (Grupo I)}

$\mathrm{Na}$ interface do material, o tecido pulpar apresentava-se infiltrado ora por leucócitos polimorfonucleares tipo neutrófilos ora por mononucleados. O tecido pulpar nesta interface estava organizado e células começam se organizar em paliçada justapostas a um material escuro e granular, simulando a organização de nova camada odontoblástica. Algumas células apresentam grânulos do material granular escuro no seu interior, indicando que macrófagos migraram para o tecido pulpar e fagocitaram o material. Não foi evidenciado qualquer sinal de dentinogênese ou de barreira dentinária, mesmo nas paredes laterais, no terço médio da polpa radicular, distante da superfície de corte. Em poucos espécimes notaram-se focos de dentino-osteogênese caracterizados por matriz óssea permeada por células semelhantes a osteoblastos, irregularmente distribuídas, gerando uma área semelhante a osso primário também conhecido como osso imaturo ou osso embrionário. Não foram observados sinais de dentina reacional nas paredes laterais.

Neste grupo experimental, em todos os espécimes observados, nos planos mais profundos da polpa, destaca-se o acúmulo de células mononucleadas em focos concentrados semelhante a macrófagos vacuolados. No terço médio da polpa radicular, na maioria dos espécimes, notou-se uma hemorragia exuberante com eritrócitos dispostos irregularmente e difusamente pelos espaços extracelulares do conjunto. 0 ligamento periodontal estava íntegro. O osso alveolar não apresentava áreas de reabsorção, havendo elevada presença de osteoblastos em sua superfície. (Figura 1). 


\section{Figura 1 - Grupo I - Derivado da Matriz do Esmalte (Emdogain ${ }^{\circledR}$ ) (7 dias)}

A e B - Terço cervical e médio do canal radicular evidenciando tecido pulpar (P) alterado com áreas hemorrágicas. HE ZEISS 20x.

C e D - Detalhe das figuras A e B, evidenciando as áreas de hemorragia. HE ZEISS 40 e $60 \times$.

E - Terço apical mostrando tecido pulpar normal e camada odontoblástica normal. HE ZEISS $20 \times$.

F e G - Ligamento periodontal (L) normal. Ausência de células inflamatórias e presença intensa de fibras colágenas (seta) HE ZEISS 20 e 40x.

H - Radiografia periapical evidenciando integridade da lâmina dura e ausência de alterações no tecido ósseo. 

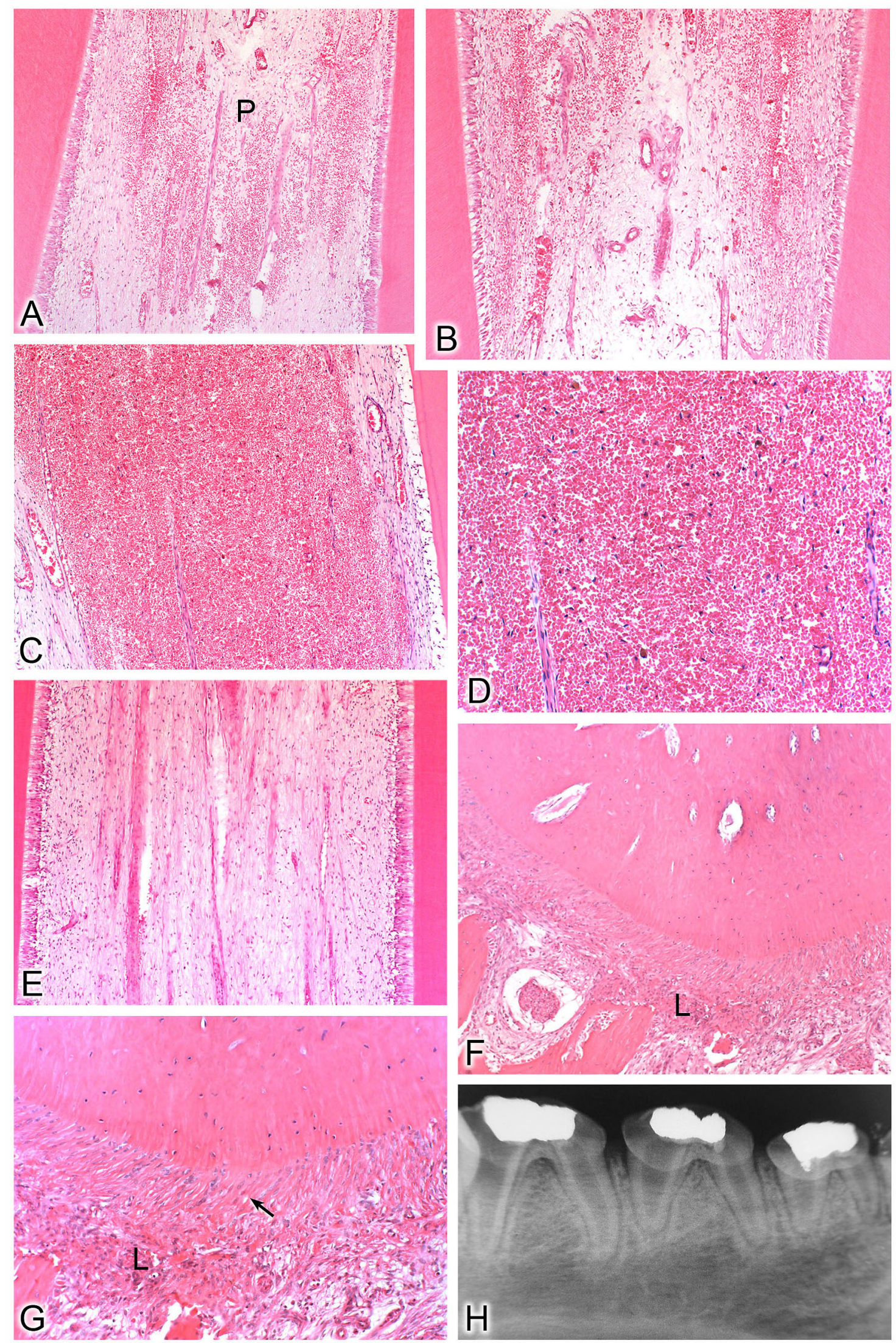
70 dias (Grupo IV)

Neste período experimental, todos seus espécimes apresentaram necrose do tecido pulpar e lesão periapical. Não foi observada ponte de dentina em nenhum espécime deste grupo, estando a camada odontoblástica ausente ao longo das paredes dentinárias. A superfície do cemento era irregular devido às áreas de reabsorção, as quais formavam lacunas cementárias, algumas com presença de células clásticas. No ligamento periodontal, células inflamatórias do tipo mononucleares e polimorfonucleares se encontravam mais concentradas junto ao ápice, formando um ou mais focos. Havia edema generalizado e escassa presença de células. O osso alveolar mostrava áreas de reabsorção não reparadas determinando um aumento acentuado da região periapical (Figura 2). 


\section{Figura 2 -Grupo IV - Derivado da Matriz do Esmalte (Emdogain ${ }^{\circledR}$ ) (70 dias)}
A e B - Tecido pulpar necrosado e ausência de ponte de dentina. HE ZEISS 20 e 40x.
C - Terço médio do canal radicular evidenciando tecido pulpar necrosado. HE ZEISS $20 \times$.
D - Região apical e periapical evidenciando ligamento periodontal com presença de células inflamatórias, edema generalizado (e) e dissociação fibrilar. Nos tecidos mineralizados, cemento e osso, presença de áreas de reabsorção e de osteoclasto (círculo) na superfície óssea. HE ZEISS 60×.
E - Radiografia periapical evidenciando perda da integridade da lâmina dura e presença de áreas radiolúcidas sugestivas de reação periapical crônica (seta). 

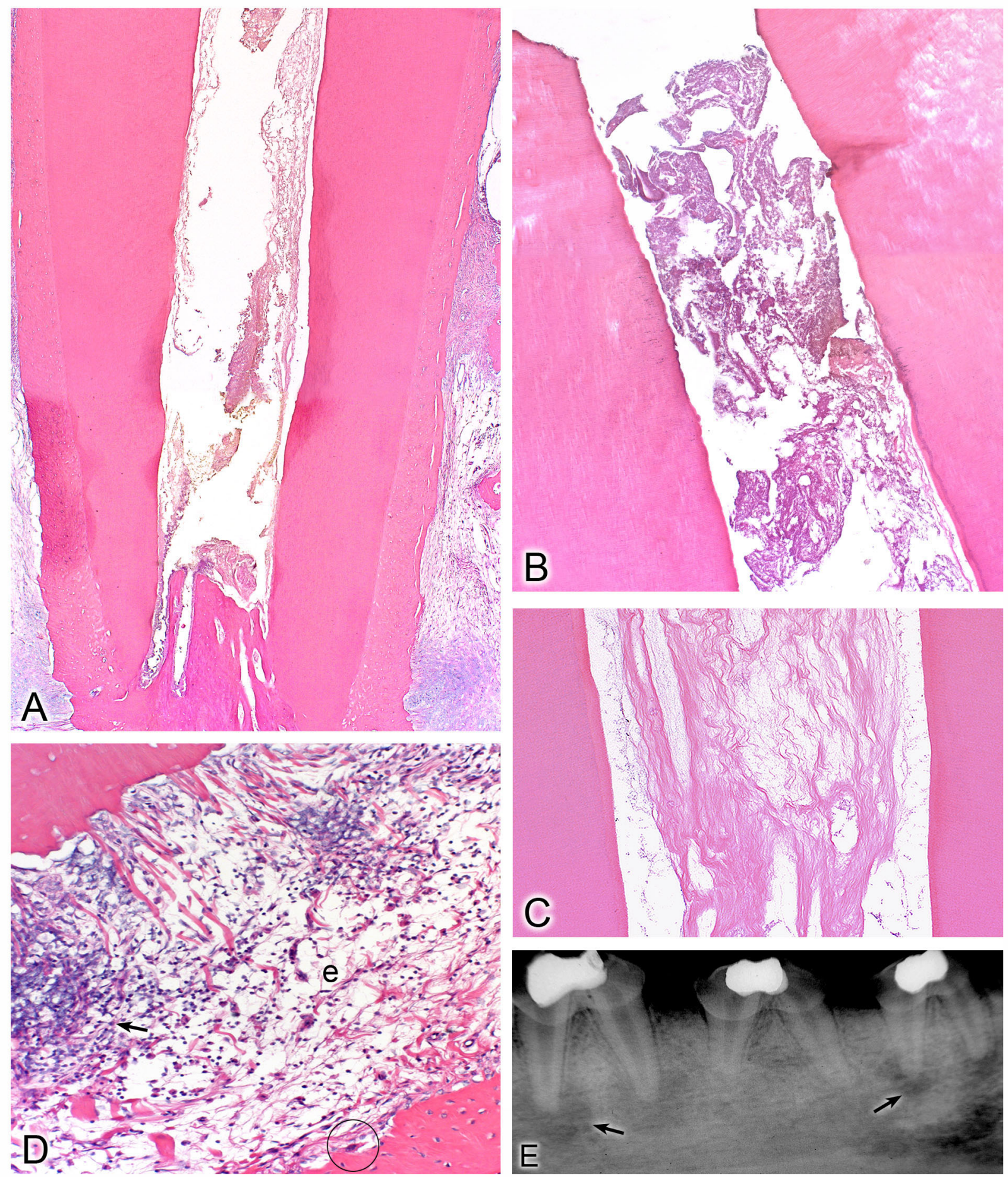


\section{Hidróxido de Cálcio}

\section{7 dias (Grupo II)}

$\mathrm{Na}$ interface do material com o tecido pulpar observou-se uma faixa de necrose por coagulação, caracterizada por uma faixa eosinofílica desorganizada. Nesta interface, no tecido pulpar, havia infiltração de neutrófilos e leucócitos mononucleados em alguns espécimes. Em outros, o tecido pulpar apresentava uma camada odontoblástica nova, com disposição em paliçada destas células. Nas paredes laterais havia uma fina e organizada barreira de dentina. Os vasos subjacentes encontravam-se congestos. Em algumas áreas foi observada uma avançada organização da nova camada de odontoblastos. As regiões apical e periapical também eram íntegras. No ligamento periodontal não haviam células inflamatórias, sendo observada intensa presença de células e fibras que partiam do cemento e se inseriam no osso alveolar, em meio a um tecido conjuntivo denso e vascularizado (Figura 3).

\section{0 dias (Grupo V)}

A polpa, na interface com o material, apresentou características de normalidade, apresentando estruturas normais, com camada odontoblástica madura e organizada e produção de dentina terciária bem organizada especialmente em suas camadas mais profundas. Nas camadas mais superficiais da barreira dentinária espessa (Escore 3), observou-se algumas inclusões celulares e invaginação de tecido pulpar. Nas regiões apical e periapical o cemento era regular, o ligamento periodontal apresentava tecido conjuntivo denso, ausência de células inflamatórias e intensa presença de fibras colágenas e o osso alveolar apresentava elevada presença de osteoblastos alinhados em sua superfície (Figura 3). 


\section{Figura 3 - Grupo II - Hidróxido de Cálcio (7 dias)}

A - Tecido pulpar (P) e camada odontoblástica (seta) normais. HE ZEISS 20x.

B - Região apical e periapical. Ligamento periodontal normal com presença de fibras de Sharpey (seta); cemento (C) e osso alveolar (O) normais. HE ZEISS 20x.

\section{Grupo V - Hidróxido de Cálcio}

(70 dias)

C - Ponte de dentina (D) em contato direto com o material capeador. Tecido pulpar (P) normal. HE ZEISS 20x.

$D$ - Terço médio do canal radicular evidenciando tecido pulpar íntegro $(P)$ e camada odontoblástica normal. HE ZEISS 20x.

E - Detalhe da figura B evidenciando em maior aumento a camada odontoblástica normal (seta). HE ZEISS 40X.

F - Região apical e periapical normais. Ligamento periodontal normal $(L)$ e intensa presença de fibras de Sharpey (seta). HE ZEISS 20x. 


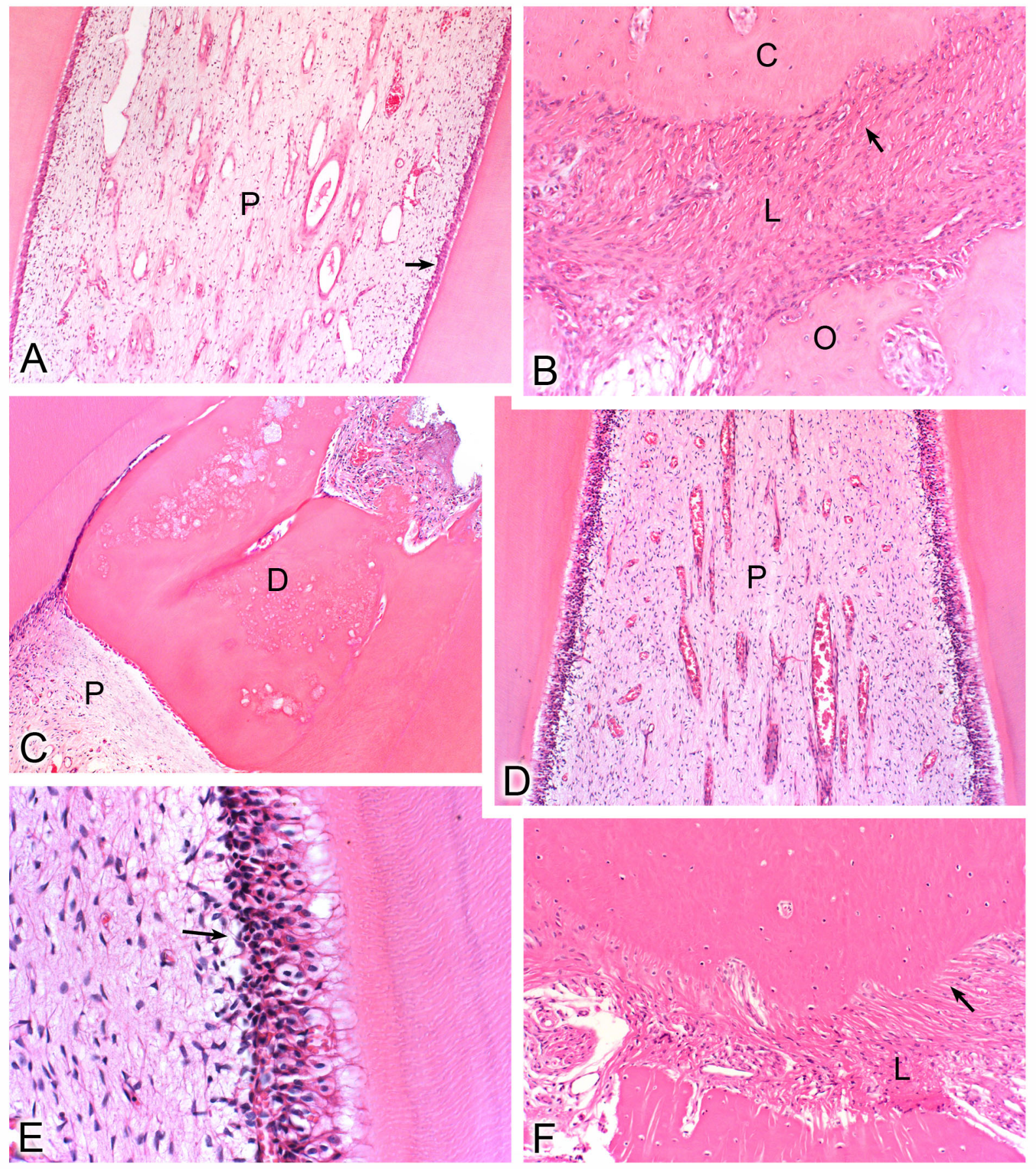




\section{Óxido de Zinco e Eugenol}

7 dias (Grupo III)

$\mathrm{Na}$ interface do material com a polpa dentária observou-se um infiltrado inflamatório predominantemente mononuclear, com eventuais polimorfonucleares de tipo neutrófilos. No tecido pulpar subjacente os vasos sanguíneos estavam congestos. Em alguns espécimes notou-se fragmentos de dentina (esquirulas). Em alguns cortes notou-se uma quantidade maior de neutrófilos com focos de liquefação (abscedeção). Em um dos espécimes, a inflamação intensa se estendia mais profundamente na polpa radicular. No ápice radicular, os canais do delta se encontravam aumentados e preenchidos por tecido conjuntivo íntegro. Não havia áreas de reabsorção na superfície do cemento. O ligamento periodontal mostrava intensa quantidade de fibras colágenas (Figura 4).

\section{0 dias (Grupo VI)}

Neste grupo, não ocorreu a formação de ponte de tecido mineralizado em nenhum espécime. O tecido pulpar encontrava-se inflamado com moderada quantidade de células inflamatórias mononucleares em todas as raízes, entre as quais era observada discreta presença de polimorfonucleares. Áreas de dissociação fibrilar eram frequentes em todo o tecido pulpar, acompanhadas de edema e pontos de necrose. A superfície do cemento apical apresentava áreas de reabsorção não reparadas. Na região do ápice radicular, as foraminas encontravam-se ampliadas e com restos teciduais inflamados em seu interior. O ligamento periodontal estava ampliado com presença de infiltrado inflamatório de grau predominantemente moderado e edema generalizado. $O$ tecido ósseo alveolar apresentava-se reabsorvido e não reparado (Figura 4). 


\section{Figura 4 - Grupo III - Óxido de Zinco e Eugenol (7 dias)}

A - Tecido pulpar (P) e camada odontoblástica (seta) normais no terço médio do canal radicular. HE ZEISS 20x.

B - Região apical e periapical. Ligamento periodontal ( $L$ ) normal com intensa presença de fibras de Sharpey (seta); cemento, (C) e osso (O) normais. HE ZEISS 20×.

\section{Grupo VI - Óxido de Zinco e Eugenol (70 dias)}

C - Ausência de ponte de dentina. Tecido pulpar inflamado (P) com moderada quantidade de células inflamatórias, predominantemente mononucleadas. HE ZEISS $20 \times$.

D - Terço médio do canal radicular evidenciando tecido pulpar com nítida alteração tecidual, fibrose e áreas de necrose. HE ZEISS 20×.

E - Tecido pulpar alterado evidenciando intensa fibrose. Tricrômico de Mallory. ZEISS $20 x$.

F - Ligamento periodontal evidenciando infiltrado inflamatório severo próximo ao ápice radicular, presença de edema e dissociação fibrilar. HE ZEISS 20×.

G - A radiografia periapical mostra a perda de integridade da lâmina dura e a presença de área radiolúcida sugestiva de reação periapical crônica (seta). 

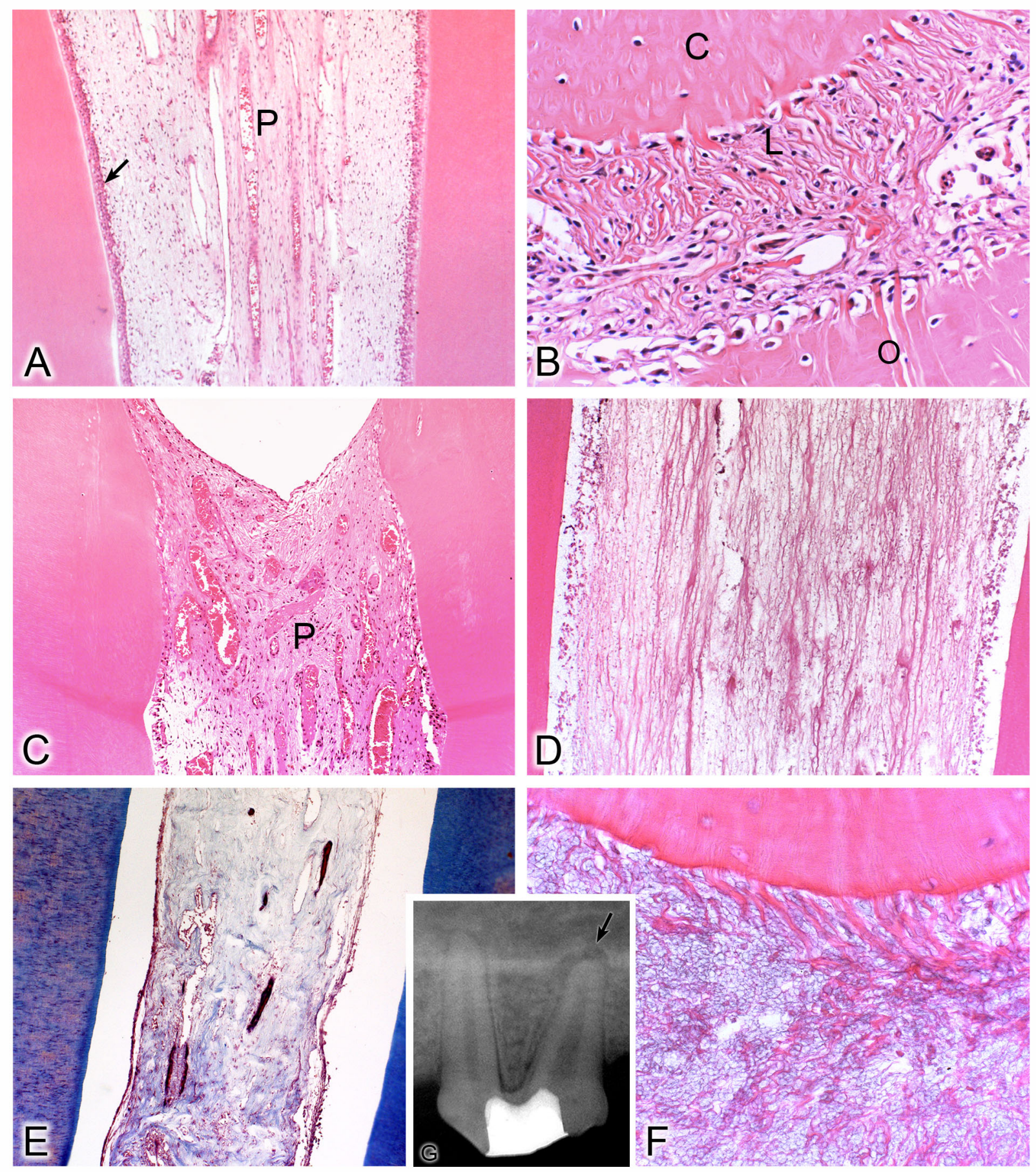
Quadro 1 - Resultados da análise microscópica do tecido pulpar, 7 e 70 dias após a realização da pulpotomia, com relação à espessura da barreira dentinária, severidade da inflamação, presença ou ausência de hemorragia, presença ou ausência de osteogênese focal e presença ou ausência de necrose pulpar. Valores expressos em número de dentes.

\begin{tabular}{|c|c|c|c|c|c|c|c|c|c|}
\hline \multirow{2}{*}{\begin{tabular}{|c|} 
Parâmetro \\
Espessura da barreira
\end{tabular}} & Escore & \multicolumn{2}{|r|}{$\begin{array}{l}\text { 7ias } \\
\text { Hidróxido de Cálcio }\end{array}$} & & \multicolumn{3}{|c|}{70 dias } & \multicolumn{2}{|c|}{$\begin{array}{l}\text { Comparação entre } \\
\text { periodos }\end{array}$} \\
\hline & $\mathbf{0}$ & $\frac{(n=12)}{8}$ & $\begin{array}{c}(n=4) \\
4\end{array}$ & $\frac{\text { Eugenol }(\mathrm{n}=4)}{4}$ & $\begin{array}{c}\text { Emdogain } \\
(\mathbf{n}=12) \\
-^{\#}\end{array}$ & $\begin{array}{l}\text { Hidróxido de Cálcio } \\
(\mathrm{n}=3)\end{array}$ & $\begin{array}{l}\text { Óxido de Zinco e } \\
\text { Eugenol }(n=3)\end{array}$ & EMD & ${ }_{-4}^{\#}$ \\
\hline & 1 & 2 & 0 & 0 & .\# & 1 & 1 & $\mathrm{HC}$ & $p=0.0357 *$ \\
\hline & 2 & 0 & 0 & 0 & -\# & 1 & 0 & $\mathrm{ZOE}$ & $p=0.0384 *$ \\
\hline & & 0 & 0 & 0 & $-\#$ & 1 & 0 & & \\
\hline & Não observável & 2 & 0 & 0 & 0 & 0 & 0 & & \\
\hline \multicolumn{2}{|l|}{ Comparação entre grupos } & \multicolumn{3}{|c|}{$p=0,063$} & \multicolumn{3}{|c|}{$p=0,0975$} & & \\
\hline Severidade da inflamação & $\mathbf{0}$ & 2 & 3 & 0 & $-\#$ & 1 & 0 & EMD & $-\#$ \\
\hline & 1 & 6 & 1 & 1 & $-\#$ & 2 & 3 & $\mathrm{HC}$ & $p=0,1535$ \\
\hline & 2 & 4 & 0 & 1 & ${ }^{*}$ & 0 & 0 & ZOE & $p=0,0111^{*}$ \\
\hline & & 0 & 0 & 2 & $-\#$ & 0 & 0 & & \\
\hline & Não observável & 0 & 0 & 0 & 0 & 0 & 0 & & \\
\hline \multicolumn{2}{|l|}{ Comparação entre grupos } & \multicolumn{3}{|c|}{$\begin{array}{c}p=0,0002^{*} \\
\mathrm{EMD} \times \mathrm{HC}=p<0,05^{*} ; \mathrm{EMD} \times \mathrm{ZOE}=p>0,05 ; \mathrm{HC} \times \mathrm{ZOE}=p<0,05 *\end{array}$} & \multicolumn{3}{|c|}{$p=0,1740$} & & \\
\hline \multirow{2}{*}{ Hemorragia } & $\mathbf{0}$ & 0 & 4 & 4 & $-\#$ & 3 & 3 & \multirow{3}{*}{$\begin{array}{l}\text { EMD } \\
\text { HC } \\
\text { ZOE }\end{array}$} & $-\#$ \\
\hline & 1 & 12 & 0 & 0 & -\# & 0 & 0 & & $p>0,05$ \\
\hline Comparação entre grupos & & \multicolumn{3}{|c|}{$\begin{aligned} p & <0,0001^{*} \\
\mathrm{EMD} \times \mathrm{HC}=p<0,05 * ; & \mathrm{EMD} \times \mathrm{ZOE}=p<0,05 * ; \mathrm{HC} \times \mathrm{ZOE}=p>0,05\end{aligned}$} & \multicolumn{3}{|c|}{$p>0,05$} & & $p>0,05$ \\
\hline \multirow[t]{3}{*}{ Osteodentinogênese focal } & 0 & 4 & 4 & 4 & $-\#$ & 3 & 3 & \multirow{4}{*}{$\begin{array}{l}\text { EMD } \\
\text { HC } \\
\text { ZOE }\end{array}$} & $-\#$ \\
\hline & 1 & 6 & 0 & 0 & $-\#$ & 0 & 0 & & $p>0,05$ \\
\hline & Não observável & \multirow{2}{*}{\multicolumn{3}{|c|}{$\begin{array}{c}p<0,0001^{*} \\
\mathrm{EMD} \times \mathrm{HC}=p<0,05^{*} ; \mathrm{EMD} \times \mathrm{ZOE}=p<0,05^{*} ; \mathrm{HC} \times \mathrm{ZOE}=p>0,05\end{array}$}} & 0 & & 0 & & $p>0,05$ \\
\hline Comparação entre grupos & & & & & \multicolumn{3}{|c|}{$p>0,05$} & & \\
\hline \multirow[t]{2}{*}{ Necrose } & $\mathbf{0}$ & 12 & 4 & 4 & 0 & 3 & 3 & \multirow{3}{*}{$\begin{array}{l}\text { EMD } \\
\text { HC } \\
\text { ZOE }\end{array}$} & $p<0,001^{*}$ \\
\hline & 1 & 0 & 0 & 0 & 12 & 0 & 0 & & $p>0,05$ \\
\hline Comparação entre grupos & & \multicolumn{3}{|c|}{$p>0,05$} & \multicolumn{3}{|c|}{$\begin{array}{c}p<0,0001^{*} \\
\mathrm{EMD} \times \mathrm{HC}=p<0,05^{*} ; \mathrm{EMD} \times \mathrm{ZOE}=p<0,05^{*} ; \mathrm{HC} \times \mathrm{ZOE}=p>0,05\end{array}$} & & $p>0,05$ \\
\hline
\end{tabular}

\# necrose pulpar, não foi possível avaliar; * estatisticamente significante. 
Quadro 2 - Resultados da análise microscópica da região periapical, 7 e 70 dias após a realização da pulpotomia, com relação presença ou ausência de reabsorção radicular externa e espessura do ligamento periodontal. Valores expressos em número de dentes.

\begin{tabular}{|c|c|c|c|c|c|c|c|c|c|}
\hline \multirow{4}{*}{$\begin{array}{l}\text { Parâmetro } \\
\begin{array}{l}\text { Reabsorção radicular } \\
\text { externa }\end{array}\end{array}$} & \multirow[b]{2}{*}{ Escore } & \multicolumn{3}{|c|}{7 dias } & \multicolumn{3}{|c|}{70 dias } & \multirow{2}{*}{\multicolumn{2}{|c|}{ Comparação entre períodos }} \\
\hline & & 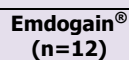 & $\begin{array}{c}\text { Hidróxido de Cálcio } \\
(\mathrm{n}=4)\end{array}$ & $\begin{array}{c}\text { Óxido de Zinco e } \\
\text { Eugenol }(n=4)\end{array}$ & $\begin{array}{c}\text { Emdogain }_{(\mathrm{n}=12)} \\
(\mathrm{n})\end{array}$ & $\begin{array}{c}\text { Hidróxido de Cálcio } \\
(\mathrm{n}=3)\end{array}$ & $\begin{array}{l}\text { Óxido de Zinco e } \\
\text { Eugenol }(n=3)\end{array}$ & & \\
\hline & 0 & 12 & 4 & 4 & 1 & 3 & 1 & \multirow{3}{*}{$\begin{array}{l}\text { EMD } \\
\text { HC } \\
\text { ZOE }\end{array}$} & \multirow{3}{*}{$\begin{array}{c}p<0,0001^{*} \\
p>0,05 \\
p<0,0025^{*}\end{array}$} \\
\hline & 1 & 0 & 0 & 0 & 11 & 0 & 2 & & \\
\hline \multicolumn{2}{|l|}{ Comparação entre grupos } & \multicolumn{3}{|c|}{$p>0,05$} & \multicolumn{3}{|c|}{$\begin{array}{c}p=0,0004 \\
\mathrm{EMD} \times \mathrm{HC}=p<0,05^{*} ; \mathrm{EMD} \times \mathrm{ZOE}=p>0,05 ; \mathrm{HC} \times \mathrm{ZOE}=p<0,05^{*}\end{array}$} & & \\
\hline Espessura do & $\mathbf{0}$ & 12 & 4 & 4 & 0 & 2 & 0 & EMD & $p<0,001^{*}$ \\
\hline \multirow[t]{3}{*}{ ligamento periodontal } & 1 & 0 & 0 & 0 & 2 & 1 & 1 & $\mathrm{HC}$ & $p>0,3123$ \\
\hline & & 0 & 0 & 0 & 7 & 0 & 2 & ZOE & $p<0,006^{*}$ \\
\hline & 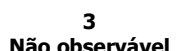 & 0 & $\begin{array}{l}0 \\
0\end{array}$ & 0 & $\begin{array}{l}3 \\
0\end{array}$ & 0 & 0 & & \\
\hline \multirow{2}{*}{\multicolumn{2}{|c|}{ Comparação entre grupos }} & \multirow{2}{*}{\multicolumn{3}{|c|}{$p>0,05$}} & \multirow{2}{*}{\multicolumn{3}{|c|}{$\begin{aligned} & p=0,0007 \\
& \mathrm{EMD} \times \mathrm{HC}=p<0,05^{*} ; \mathrm{EMD} \times \mathrm{ZOE}=p>0,05 ; \mathrm{HC} \times \mathrm{ZOE}=p<0,05 *\end{aligned}$}} & & \\
\hline & & & & & & & & & \\
\hline
\end{tabular}

* estatisticamente significante. 


\subsection{Resultados radiográficos}

As radiografias foram avaliadas por 3 examinadores calibrados $(\kappa=0,928)$, com relação à presença ou ausência da lâmina dura, de áreas de rarefação óssea periapical, de reabsorções radiculares (interna e externa) e de ponte de dentina.

No período experimental de 7 dias, os grupos I (Emdogain ${ }^{\circledR}$ ), II (Hidróxido de cálcio) e III (Oxido de zinco e eugenol) apresentaram integridade da lâmina dura, ausência de rarefação óssea periapical, ausência de reabsorção interna e externa detectáveis radiograficamente e ausência de formação de ponte dentinária em contato com o material protetor (Tabela 3).

No período experimental de 70 dias, o Grupo IV (Emdogain ${ }^{\circledR}$ ) apresentou descontinuidade de lâmina dura com presença de rarefação óssea periapical em 100\% dos casos. Ainda, reabsorção radicular interna e formação de ponte dentinária não foram observadas, com reabsorção radicular externa presente em $75 \%$ dos casos. Nos grupos V (Hidróxido de cálcio) e VI (Óxido de zinco e eugenol), a descontinuidade da lâmina dura e presença de rarefação periapical foi observada em $25 \%$ e $50 \%$ dos casos, respectivamente, e reabsorção radicular externa em $25 \%$ dos casos. A presença de reabsorção radicular interna e formação de ponte dentinária não foi observada em nenhum dos grupos (Tabela 3).

No período de 70 dias foram observadas áreas de rarefação óssea periapical sugestivas de lesão periapical nos espécimes dos Grupos IV, V e VI. A quantificação da extensão dessas lesões foi obtida por meio da mensuração das áreas radiolúcidas para cada raiz, utilizando o programa Image J $1.37 \mathrm{u}$, sendo os valores expressos em $\mathrm{mm}^{2}$.

Para realização da análise estatística, as medidas das áreas de rarefação óssea periapical sugestivas de lesão periapical foram inseridas em um teste preliminar para verificar a normalidade da distribuição amostral. Como os valores apresentavam distribuição não-normal, foi utilizado o teste não-paramétrico de Kruskal-Wallis, ao nível de significância de 5\%, para comparação das medidas das áreas radiolúcidas na região periapical entre os 3 grupos estudados.

As lesões periapicais apresentavam maior extensão nos espécimes do Grupo IV (Emdogain ${ }^{\circledR} ; p<0,05$ ), seguido pelas lesões do Grupo VI (Óxido de zinco e eugenol; $p$ $<0,05$ ) e Grupo V 5 (Hidróxido de cálcio; $p<0,05$ ) (Tabela 4). 
Tabela 3 - Resultados da avaliação radiográfica 7 e 70 dias após a realização da pulpotomia com relação à integridade da lâmina dura, presença de áreas de rarefação óssea, de reabsorção radicular externa e de formação de ponte dentinária. Valores expressos em número de dentes e porcentagem.

\begin{tabular}{|c|c|c|c|c|c|c|c|c|c|c|}
\hline & \multicolumn{2}{|c|}{$\begin{array}{c}\text { Integridade da } \\
\text { lâmina dura }\end{array}$} & \multicolumn{2}{|c|}{$\begin{array}{c}\text { Rarefação óssea } \\
\text { Periapical }\end{array}$} & \multicolumn{2}{|c|}{$\begin{array}{c}\text { Reabsorção } \\
\text { interna }\end{array}$} & \multicolumn{2}{|c|}{$\begin{array}{c}\text { Reabsorção } \\
\text { externa }\end{array}$} & \multicolumn{2}{|c|}{ Ponte dentinária } \\
\hline & $\begin{array}{c}\text { Ausente } \\
\text { n (\%) }\end{array}$ & $\begin{array}{c}\text { Presente } \\
\text { n (\%) }\end{array}$ & $\begin{array}{c}\text { Ausente } \\
\text { n (\%) }\end{array}$ & $\begin{array}{c}\text { Presente } \\
\text { n (\%) }\end{array}$ & $\begin{array}{c}\text { Ausente } \\
\text { n (\%) }\end{array}$ & $\begin{array}{c}\text { Presente } \\
\text { n (\%) }\end{array}$ & $\begin{array}{c}\text { Ausente } \\
\text { n (\%) }\end{array}$ & $\begin{array}{c}\text { Presente } \\
\text { n (\%) }\end{array}$ & $\begin{array}{c}\text { Ausente } \\
\text { n (\%) }\end{array}$ & $\begin{array}{c}\text { Presente } \\
\text { n (\%) }\end{array}$ \\
\hline $\begin{array}{l}\text { Emdogain }^{\circledR} \\
\text { (7 dias) }\end{array}$ & 0 & $\begin{array}{c}12 \\
(100 \%)\end{array}$ & $\begin{array}{c}12 \\
(100 \%)\end{array}$ & 0 & $\begin{array}{c}12 \\
(100 \%)\end{array}$ & 0 & $\begin{array}{c}12 \\
(100 \%)\end{array}$ & 0 & $\begin{array}{c}12 \\
(100 \%)\end{array}$ & 0 \\
\hline $\begin{array}{l}\text { Hidróxido } \\
\text { de Cálcio } \\
\text { (7 dias) }\end{array}$ & 0 & $\begin{array}{c}4 \\
(100 \%)\end{array}$ & $\begin{array}{c}4 \\
(100 \%)\end{array}$ & 0 & $\begin{array}{c}4 \\
(100 \%)\end{array}$ & 0 & $\begin{array}{c}4 \\
(100 \%)\end{array}$ & 0 & $\begin{array}{c}4 \\
(100 \%)\end{array}$ & 0 \\
\hline $\begin{array}{l}\text { Óxido de } \\
\text { Zinco e } \\
\text { Eugenol } \\
\text { (7 dias) }\end{array}$ & 0 & $\begin{array}{c}4 \\
(100 \%)\end{array}$ & $\begin{array}{c}4 \\
(100 \%)\end{array}$ & 0 & $\begin{array}{c}4 \\
(100 \%)\end{array}$ & 0 & $\begin{array}{c}4 \\
(100 \%)\end{array}$ & 0 & $\begin{array}{c}0 \\
(100 \%)\end{array}$ & 0 \\
\hline $\begin{array}{l}\text { Emdogain }^{\circledR} \\
(70 \text { dias })\end{array}$ & $\begin{array}{c}12 \\
(100 \%)\end{array}$ & 0 & 0 & $\begin{array}{c}12 \\
(100 \%)\end{array}$ & $\begin{array}{c}12 \\
(100 \%)\end{array}$ & 0 & $\begin{array}{c}3 \\
(25 \%)\end{array}$ & $\begin{array}{c}9 \\
(75 \%)\end{array}$ & $\begin{array}{c}12 \\
(100 \%)\end{array}$ & 0 \\
\hline $\begin{array}{l}\text { Hidróxido } \\
\text { de Cálcio } \\
\text { (70 dias) }\end{array}$ & $\begin{array}{c}1 \\
(25 \%)\end{array}$ & $\begin{array}{c}3 \\
(75 \%)\end{array}$ & $\begin{array}{c}3 \\
(75 \%)\end{array}$ & $\begin{array}{c}1 \\
(25 \%)\end{array}$ & $\begin{array}{c}4 \\
(100 \%)\end{array}$ & 0 & $\begin{array}{c}3 \\
(75 \%)\end{array}$ & $\begin{array}{c}1 \\
(25 \%)\end{array}$ & $\begin{array}{c}4 \\
(100 \%)\end{array}$ & 0 \\
\hline $\begin{array}{l}\text { Óxido de } \\
\text { Zinco e } \\
\text { Eugenol } \\
\text { (70 dias) }\end{array}$ & $\begin{array}{c}2 \\
(50 \%)\end{array}$ & $\begin{array}{c}2 \\
(50 \%)\end{array}$ & $\begin{array}{c}2 \\
(50 \%)\end{array}$ & $\begin{array}{c}2 \\
(50 \%)\end{array}$ & $\begin{array}{c}4 \\
(100 \%)\end{array}$ & 0 & $\begin{array}{c}3 \\
(75 \%)\end{array}$ & $\begin{array}{c}1 \\
(25 \%)\end{array}$ & $\begin{array}{c}4 \\
(100 \%)\end{array}$ & 0 \\
\hline
\end{tabular}

Tabela 4 - Medidas das áreas radiolúcidas sugestivas de lesão periapical, 70 dias após a realização da pulpotomia, nos grupos IV, V e VI. Valores expressos em $\mathrm{mm}^{2}$.

\begin{tabular}{cccc}
\hline & $\begin{array}{c}\text { Emdogain }^{\circledR} \\
(\mathbf{n}=\mathbf{2 4} \text { raízes })\end{array}$ & $\begin{array}{c}\text { Hidróxido de Cálcio } \\
(\mathbf{n}=\mathbf{8} \text { raízes })\end{array}$ & $\begin{array}{c}\text { Óxido de Zinco } \mathbf{c} \\
\text { Eugenol } \\
(\mathbf{n}=\mathbf{8} \text { raízes })\end{array}$ \\
\hline Mediana & 9,71 & 0 & 2,2 \\
$(\mathbf{Q 1 - Q 3 )}$ & $(7,22-13,04)$ & $(0-0,89)$ & $(0-5,39)$ \\
\hline
\end{tabular}




\section{DIscussão}





\section{DISCUSSÃo}

\section{Emdogain $^{\circledR}$}

O objetivo da pulpotomia é que após o procedimento operatório, o material protetor aplicado sobre a exposição pulpar possa induzir uma resposta reparativa dentinogênica levando à formação de ponte de dentina. Até o momento o hidróxido de cálcio ainda é o material de escolha para este capeamento. No entanto, diversos agentes bioativos têm sido desenvolvidos para o capeamento pulpar, incluindo o derivado da matriz do esmalte. O derivado da matriz do esmalte é aplicado na área da Periodontia para obter a regeneração biológica da perda de inserção dental por promover a proliferação, a migração e a diferenciação de fibroblastos do ligamento periodontal, cobrindo a superfície radicular exposta (Heijl et al., 1997; Rasperini et al., 1999). Embora este material venha sendo amplamente estudado na área da Periodontia, poucos estudos têm sido direcionados à avaliação do uso desse material nas terapias conservadoras do tecido pulpar.

Alguns estudos tem hipoteticamente sugerido a participação do derivado da matriz do esmalte na regeneração e estimulação de mineralização no tecido conjuntivo pela "provável" indução da diferenciação de odontoblastos e subseqüente formação de dentina reparadora (Nakamura et al., 2001; Nakamura et al., 2002), assim como pela estimulação de células da polpa dental produzirem matriz colagênica para mineralização (Ishizaki et al., 2003; Nakamura et al., 2004). Em estudos prévios realizados em porcos-miniatura (Nakamura et al., 2002) foi observado o selamento da exposição pulpar em sua totalidade em resposta ao uso de derivado da matriz do esmalte. Segundo estes autores, seus resultados suportaram a hipótese de que certas proteínas da matriz do esmalte, como amelogeninas, participam na diferenciação e maturação de células odontoblásticas e que estas moléculas desempenham um papel importante durante a formação de dentina.

Nossos resultados, comparando os efeitos do derivado da matriz do esmalte e do hidróxido de cálcio sobre o tecido pulpar, em pulpotomias, são semelhantes aos encontrados por Olsson et al. (2005) e divergentes dos resultados encontrados por Nakamura et al. (2002). Sendo o Emdogain ${ }^{\circledR}$ um material de consistência gelatinosa, haveria uma tendência de proliferação do tecido pulpar em direção coronária, no sentido de ocupar o espaço deste material. Este fato, poderia justificar, do ponto de vista físico-mecânico a capacidade deste material de formar ilhotas de material 
mineralizado no tecido pulpar exposto, abaixo da exposição, e ao mesmo tempo sua incapacidade de formar ponte dentinária no local da exposição pulpar. Desta forma, talvez a utilização de um material semi-sólido como veículo da matriz derivada do esmalte, possa ser mais aplicável para a formação de ponte dentinária em exposições pulpares, conforme sugerido por Olsson et al. (2005).

No grupo do Emdogain ${ }^{\circledR}$ aos 7 dias, apesar do tecido estar organizado e as células começarem a se organizar em paliçada simulando uma organização de nova camada odontoblástica, não houve qualquer sinal de dentinogênese ou de barreira dentinária, tanto nas paredes laterais, como no terço médio da polpa radicular ou distante da superfície de corte. Notaram-se focos de dentino-osteogênese caracterizados por matriz óssea permeada por células semelhantes a osteoblastos, irregularmente distribuídas, gerando uma área semelhante a osso primário também conhecido como osso imaturo ou osso embrionário. Da mesma forma, no estudo realizado por Fransson et al. (2010), em todos os dentes tratados com o derivado da matriz do esmalte, o tecido mineralizado formou-se como massas isoladas, assim como, ao longo das superfícies de dentina primária exposta, embora a quantidade total de tecido duro variasse consideravelmente entre os diferentes dentes. 0 tecido mineralizado formado ao longo das superfícies de dentina expostas não apareceu aderido às paredes da dentina, no espaço inicialmente ocupado pelo gel, mas as áreas correspondentes à pré-dentina. Após 12 semanas, a estrutura parecida à ponte de tecido duro formada nos dentes tratados com hidróxido de cálcio, poderia ser capaz de providenciar uma barreira estrutural para proteção da polpa, enquanto que, isso seria improvável para as ilhas de tecido duro que se formaram em resposta ao derivado da matriz do esmalte (Kiatwateeratana et al., 2009; Fransson et al., 2010).

Entretanto foi observada intensa hemorragia no tecido pulpar em contato com o Emdogain ${ }^{\circledR}$, no período de 7 dias. Acredita-se que isto tenha sido causado pela consistência de gel do derivado da matriz do esmalte, que facilita sua difusão na matriz extracelular, causando a hemorragia por diapedese no tecido pulpar. Este fenômeno foi também observado Olsson et al. (2005) que sugeriu que a formulação do derivado da matriz do esmalte em alginato de propilenoglicol como veículo pode não ser apropriada ao momento de realizar o procedimento do capeamento pulpar. Segundo estes autores o uso de um material semi-sólido como um veículo, seria talvez mais apropriado para a formação de uma barreira de tecido mineralizado. A ausência de reparo foi evidenciada no período de 70 dias, quando foi observada a necrose do 
tecido pulpar e lesão periapical em todos os espécimes.

Do mesmo modo, Fransson et al. (2010) relataram que apesar de o hidróxido de cálcio e o derivado da matriz do esmalte terem estimulado a deposição de tecido mineralizado, a morfologia do tecido diferiu consideravelmente. Nos dentes tratados com hidróxido de cálcio, o tecido mineralizado foi formado como continuação da ponte dentinária cobrindo a polpa exposta, enquanto nos dentes recobertos com o derivado da matriz do esmalte a formação de tecido mineralizado foi inicialmente ocupada pelo material. Estes autores acreditam que essa diferença pode, em parte, ser devido ao veículo de alginato de propilenoglicol utilizado, uma vez que este material é gelatinoso e não deixa um recobrimento de base sólida na polpa amputada como seria feito por hidróxido de cálcio ou pelo agregado de trióxido mineral (MTA).

\section{Hidróxido de Cálcio}

Embora a primeira tentativa de capeamento pulpar tenha sido efetuada por Philip Pfaff em 1756, quando colocou uma pequena lâmina de ouro, cuidadosamente adaptada sobre a exposição pulpar, foi com a introdução por Hermann em 1920, de uma formulação contendo hidróxido de cálcio chamada Calxyl, que o sucesso dos capeamentos pulpares tornou-se realidade. Desde então, este tem sido o material mais aceito para esta finalidade (Glass e Zander, 1949; Andreasen e Andreasen, 2001; Hörsted-Bindslev et al., 2003; Accorinte et al., 2005; Assed et al., 2005; Farhad e Mohammadi, 2005; Queiroz et al., 2005; Silva et al., 2006; Silva et al., 2009).

Em função de suas propriedade biológicas satisfatórias, o hidróxido de cálcio tem sido utilizado em diversos procedimentos clínicos, incluindo proteções pulpares (Aeinehchi et al., 2003; Mestrener et al., 2003; Accorinte et al., 2005; Queiroz et al., 2005; Silva et al., 2009), pulpotomias de dentes permanentes (Assed et al., 1997; Nosrat e Nosrat, 1998) ou decíduos (Rangel et al., 1998; Ranly e Garcia-Godoy, 2000; Carrote, 2005), tratamento endodôntico de dentes permanentes com rizogênese incompleta (Leonardo et al., 1993; Silva et al., 2005), como cimento obturador de canais radiculares (Leonardo et al., 1997; Silva et al., 1997), em casos de reabsorções dentárias (Andreasen e Andreasen, 2001; Consolaro, 2005) e como curativo de demora entre sessões (Leonardo, 2005).

No presente estudo foi utilizada uma pasta de hidróxido de cálcio p.a. em soro fisiológico sobre o remanescente pulpar, após a realização da pulpotomia. Optamos por utilizar o hidróxido de cálcio p.a. em solução aquosa, pois, de acordo com a literatura, 
pastas à base de hidróxido de cálcio solúveis em água promovem maior índice de formação de barreira de tecido mineralizado (Holland et al., 1980; Holland et al., 1981). O hidróxido de cálcio foi utilizado como controle negativo, conforme recomendação da ISO 7405:2008 que considera o potencial de formação de tecido duro, na forma de ponte dentinária, quando do contato deste material com o tecido conjuntivo pulpar, após exposição induzida. A avaliação radiográfica, metodologia por nós empregada para mensurar a capacidade de formação de ponte dentinária deste material, como controle, em modelo animal, apesar de não observar a presença de ponte dentinária em nenhum caso, torna-se de extrema relevância, pois o exame radiográfico é um dos principais parâmetros para o estabelecimento de sucesso a médio e longo prazo na clínica odontológica.

No período de 7 dias, o tecido pulpar adjacente ao material apresentava infiltração de neutrófilos e leucócitos mononucleados em alguns focos e o tecido pulpar em algumas áreas já começava a formar uma camada odontoblástica nova com disposição em paliçada destas células. Nas paredes laterais foi evidenciada uma fina e organizada barreira de dentina e, em algumas áreas, foi observada uma organização avançada da nova camada de odontoblastos formada. Estes resultados também foram obtidos por Six et al. (2002) que observaram infiltrado inflamatório suave a moderado em contato com o material e a presença de células polarizadas, dispostas em paliçada, envolvidas na deposição de matriz e formação de uma ponte de dentina fina no estágio inicial.

No período de 70 dias, a polpa na interface com o material voltou a ter características organizadas e estruturas de normalidade com camada odontoblástica madura e organizada e produção de dentina terciária bem organizada especialmente em suas camadas mais profundas. Nas camadas mais superficiais da barreira dentinária espessa (Escore 3) observou-se algumas inclusões celulares e invaginação de tecido pulpar. Nas regiões apical e periapical o cemento era regular, o ligamento periodontal apresentava tecido conjuntivo denso, ausência de células inflamatórias e intensa presença de fibras colágenas e o osso alveolar apresentava elevada presença de osteoblastos em sua superfície.

Esses resultados estão de acordo com vários trabalhos descritos na literatura que utilizaram o hidróxido de cálcio como material de escolha para proteção pulpar e pulpotomia, e observaram padrão de normalidade após o procedimento (Holland et al., 1979; Holland et al., 1980; Holland et al., 1981; Sübay et al., 1993; Norsat e Norsat, 
1998; Accorinte et al., 2005; Queiroz et al., 2005; Silva et al., 2006; Silva et al., 2008). Os resultados favoráveis obtidos com a aplicação do hidróxido de cálcio sobre o tecido pulpar se devem às inúmeras propriedades satisfatórias desse material, amplamente descritas na literatura, dentre elas a biocompatibilidade (Queiroz et al., 2005), atividade antibacteriana (Foreman e Barnes, 1990; Leonardo et al., 1999; Assed et al., 2005) e propriedade higroscópica (Leonardo, 2005).

A formação de ponte de dentina é considerada um dos principais indicadores de sucesso após pulpotomia e o mecanismo pelo qual esta se forma tem sido motivo de pesquisa por vários anos (Glass e Zander, 1949; Schröder e Granath, 1971; Schröder, 1985; Oguntebi et al., 1993; Andreasen e Andreasen, 2001). Schröder e Granath, em 1971, demonstraram que após a aplicação do hidróxido de cálcio sobre o tecido pulpar exposto, ocorre formação de uma área definida de necrose superficial, auto-limitante, considerada benéfica por causar uma leve irritação, a qual estimula a polpa à defesa e reparo. Além disso, essa zona de necrose separa o material do remanescente pulpar vital, evitando a extensão da lesão tecidual. Assim, a camada de necrose funciona como uma superfície na qual células pulpares se aderem e, subsequentemente, polarizam-se. Essas células sofrem diferenciação passando a expressar marcadores intracelulares próprios da diferenciação odontoblástica (Seux et al., 1991).

Os resultados por nós obtidos, do ponto de vista microscópico e radiográfico, confirmaram as excelentes propriedades biológicas do hidróxido de cálcio, quando utilizado após pulpotomia.

\section{Óxido de Zinco e Eugenol}

Embora o eugenol venha sendo amplamente utilizado na Odontologia, incorporado a diversos materiais, essa substância pode ocasionar danos aos tecidos em função de sua citoxicidade, a qual desencadeia a degeneração do tecido mucoso e morte de fibroblastos, além de dermatite de contato e reação alérgica (Barkin et al., 1984; Sarrami et al., 2002). O eugenol, na dependência da concentração empregada, é capaz de inibir a respiração, divisão celular e até causar a morte das células (Hume, 1986; Markowitz et al., 1992).

Utilizamos o óxido de zinco e eugenol como controle positivo neste estudo, uma vez que de acordo com a literatura consultada e as recomendações da ISO 7405:2008, este material em contato com o tecido pulpar ocasiona histologicamente reação inflamatória variando de crônica a pulpite supurativa aguda, com presença de linfócitos 
e polimorfonucleares (Watts e Paterson, 1987; Holland et al., 1981; Fadavi e Anderson, 1996; Silva et al., 2006).

De forma global, os resultados insatisfatórios obtidos com o óxido de zinco e eugenol no período de 70 dias, em nosso trabalho, estão de acordo com a literatura (Holland et al., 1981; Watts e Paterson, 1987; Fadavi e Anderson, 1996; Silva et al., 2006; Silva et al., 2007; Silva et al., 2008), uma vez que foi evidenciada ausência de formação de ponte de dentina na maior parte dos espécimes, infiltrado inflamatório moderado no tecido pulpar, espessura do ligamento periodontal moderadamente ampliada e reabsorção do cemento e tecido ósseo.

Fadavi e Anderson (1996) observaram, 6 semanas após pulpotomia e utilização do óxido de zinco e eugenol, a presença de necrose total do tecido pulpar em quase todos os espécimes. Nos dentes com necrose parcial, havia a presença de um infiltrado inflamatório severo, interrupção da camada odontoblástica e ausência de formação de ponte de dentina. Radiograficamente os autores observaram áreas radiolúcidas sugestivas de lesão periapical crônica em $66,6 \%$ dos casos, resultando semelhante ao obtido no presente estudo, uma vez que encontramos áreas de rarefação óssea periapical em $50 \%$ dos casos.

Assim, de acordo com os resultados obtido no presente estudo, o Óxido de Zinco e Eugenol não se mostrou um material satisfatório para ser empregado sobre o tecido pulpar exposto. 
CONCLUSÃo 



\section{CONCLUSÃo}

De acordo com a metodologia empregada e considerando os resultados obtidos pela análise histopatológica e radiográfica, pôde-se concluir que, para capeamento pulpar após pulpotomia, o Derivado da Matriz do Esmalte (Emdogain ${ }^{\circledR}$ ) não mostrou resposta tecidual satisfatória e capacidade de induzir a deposição de tecido mineralizado. 

REFERÊNCIAS 



\section{REFERÊNCIAS $^{1}$}

Accorinte MLR, Loguercio AD, Reis A, Muench A, Araújo VC. Adverse effects of human pulps after direct pulp capping with the different components from a total-etch, threestep adhesive system. Dent Mater 2005;21:599-607.

Aeinehchi M, Eslami B, Ghanbariha M, Saffar AS. Mineral trioxide aggregate (MTA) and calcium hydroxide as pulp-capping agents in human teeth: a preliminary report. Int Endod J 2003;36:225-31.

Aimetti M, Romano F, Pigella E, Piemontese M. Clinical evaluation of the effectiveness of enamel matrix proteins and autologous bone graft in the treatment of mandibular Class II furcation defects: a series of 11 patients. Int J Periodontics Restorative Dent 2007;27(5):441-7.

Albuquerque DS, Gominho LF, dos Santos RA. Histologic evaluation of pulpotomy performed with ethyl-cyanoacrylate and calcium hydroxide Avaliação histológica de pulpotomia realizada com etil-cianoacrilato e com hidróxido de cálcio. Braz Oral Res 2006; 20(3):226-30

Andreasen JO, Andreasen FM. Texto e atlas colorido de traumatismo dental. 3 ed. Porto Alegre: Artmed Editora; 2001.

Assed S, Leonardo MR, Silva LAB, Nelson-Filho P, Pinto DMG. Calcium hydroxide pulpotomy in young permanent teeth with periapical involvement. Braz Endod J $1997 ; 2: 38-42$.

Assed S, Silva LAB, Nelson-Filho P. Pulpotomia em dentes decíduos e permanentes jovens. In: Assed S. Odontopediatria: bases científicas para a prática clínica. São Paulo: Artes Médicas; 2005. p.571-612.

\footnotetext{
1 Normas internas do Programa de Pós-Graduação em Odontopediatria da FORP-USP (2009), de acordo com a International Comitte of Medicals Journals Editors. Uniform Requirements of manuscripts submitted to Medical Journal, 1997. Disponível em: http://www.mja.com.au/public/information/uniform/.html. Acesso em 10 de janeiro de 2011.
} 
Barkin ME, Bloyd J, Cohen S. Acute allergic reaction to eugenol. Oral Surg $1984 ; 57: 441-2$.

Bratthall G, Lindberg P, Havemose-Poulsen A, Holmstrup P, Bay L, Söderholm G, Norderyd O, Andersson B, Rickardsson B, Hallström H, Kullendorff B, Sköld Bell H. Comparison of ready-to-use Emdogain-gel and Emdogain in patients with chronic adult periodontitis. J Clin Periodontol 2001;28(10):923-9.

Carrotte P. Endodontic treatment for children. Br Dent J 2005;198:9-15.

Cattaneo V, Rota C, Silvestri M, Piacentini C, Forlino A, Gallanti A, Rasperini G, Cetta G. Effect of enamel matrix derivative on human periodontal fibroblasts: proliferation, morphology and root surface colonization. An in vitro study. J Periodontal Res 2003;38(6):568-74.

Consolaro A. Reabsorções dentárias nas especialidades clínicas. Dental Press International: Maringá; 2005.

Cordeiro RCL, Leonardo MR, Silva LAB, Cerri PS. Desenvolvimento de um dispositivo para padronização de tomadas radiográficas em cães. RPG 1995;2:138-40.

Fadavi S, Anderson AW. A comparison of the pulpal response to freeze-dried bone, calcium hydroxide, and zinc oxide-eugenol in primary teeth in two cynomolgus monkeys. Pediatr Dent 1996;18:52-6.

Farhad A, Mohammadi Z. Calcium hydroxide: a review. Int Dent J 2005;55:293-301.

Foreman PC, Barnes IE. A review of calcium hydroxide. Int Endod J 1990;23:283-97.

Fransson H, Petersson K, Davies JR. Dentine sialoprotein and collagen I expression after experimental pulp capping in humans using Emdogain gel. Int Endod J 2010. (In Press)

Gestrelius S, Andersson C, Lidström D, Hammarström L, Somerman M. In vitro studies on periodontal ligament cells and enamel matrix derivative. J Clin Periodontol 1997;24:685-92. 
Glass RL, Zander HA. Pulp healing. J Dent Res 1949;28:97-107.

Hammarström L, Heijl L, Gestrelius S. Periodontal regeneration in a buccal dehiscence model in monkeys after application of enamel matrix proteins. J Clin Periodontol $1997 ; 24: 669-77$.

Hammarström L. Enamel matrix, cementum development and regeneration. J Clin Periodontol 1997;24:658-68.

He J, Jiang J, Safavi KE, Spångberg LS, Zhu Q. Emdogain promotes osteoblast proliferation and differentiation and stimulates osteoprotegerin expression. Oral Surg Oral Med Oral Pathol Oral Radiol Endod 2004;97(2):239-45.

He J, King Y, Jiang J, Safavi KE, Spångberg LS, Zhu Q. Enamel matrix derivative inhibits TNF-alpha-induced apoptosis in osteoblastic MC3T3-E1 cells. Oral Surg Oral Med Oral Pathol Oral Radiol Endod 2005;99(6):761-7.

Heijl L, Heden G, Svärdström G, Ostgren A. Enamel matrix derivative (Emdogain) in the treatment of intrabony periodontal defects. J Clin Periodontol 1997;24:705-14.

Hoang AM, Oates TW, Cochran DL. In vitro wound healing responses to enamel matrix derivative. J Periodontol 2000;71(8):1270-7.

Holland R, Santana Júnior A, Souza V. Influence of apical patency and filling material on healing process of dog's teeth with vital pulp after root canal therapy. Braz Dent J 2005;16:9-16.

Holland R, Souza V, Mello W, Nery MJ, Bernabé PFE, Otoboni-Filho JA. Permeability of the hard tissue bridge formed after pulpotomy with calcium hydroxide: a histologic study. J Am Dent Assoc 1979;99:472-5.

Holland R, Souza V, Mello W, Nery MJ, Bernabé PFE, Otoboni-Filho JA. Healing process of dogs' dental pulp after pulpotomy and protection with calcium hydroxide or Dycal ${ }^{\circledR}$. Rev Fac Odont UNESP 1980;9:67-70. 
Holland R, Souza V, Mello W, Nery MJ, Bernabé PFE, Otoboni-Filho JA. The influence of the sealing material in the healing process of inflamed pulps capped with calcium hydroxide or zinc oxide-eugenol cement. Acta Odontol Pediatr 1981;2:5-9.

Horsted-Bindslev $\mathrm{P}$, Vilkinis V, Sidlauskas A. Direct capping of human pulps with a dentin bonding system or with calcium hydroxide cement. Oral Surg Oral Med Oral Pathol Oral Radiol Endod 2003;96:591-600.

Hume WR. The pharmacologic and toxicological properties of zinc oxide-eugenol. J Am Dent Assoc 1986;113:789-91.

Igarashi R, Sahara T, Shimizu-Ishiura M, Sasaki T. Porcine enamel matrix derivative enhances the formation of reparative dentine and dentine bridges during wound healing of amputated rat molars. J Electron Microsc (Tokyo) 2003;52(2):227-36.

Inai T, Kukita T, Ohsaki Y, Nagata K, Kukita A, Kurisu K. Immunohistochemical demonstration of amelogenin penetration toward the dental pulp in the early stages of ameloblast development in rat molar tooth germs. Anat Rec 1991;229(2):259-70.

International Organization for Standardization (ISO). ISO 7405: Dentistry - Preclinical evaluation of biocompatibility of medical devices used in dentistry - Test methods for dental materials. Switzerland; 2008.

Ishizaki NT, Matsumoto K, Kimura Y, Wang X, Yamashita A. Histopathological study of dental pulp tissue capped with enamel matrix derivative. J Endod 2003;29(3):176-9.

Jiang J, Fouad AF, Safavi KE, Spångberg LS, Zhu Q. Effects of enamel matrix derivative on gene expression of primary osteoblasts. Oral Surg Oral Med Oral Pathol Oral Radiol Endod 2001;91(1):95-100.

Jiang J, Goodarzi G, He J, Li H, Safavi KE, Spångberg LS, Zhu Q. Emdogain-gel stimulates proliferation of odontoblasts and osteoblasts. Oral Surg Oral Med Oral Pathol Oral Radiol Endod 2006;102(5):698-702. 
Keila S, Nemcovsky CE, Moses O, Artzi Z, Weinreb M. In vitro effects of enamel matrix proteins on rat bone marrow cells and gingival fibroblasts. J Dent Res 2004;83(2):1348.

Kiatwateeratana T, Kintarak S, Piwat S, Chankanka O, Kamaolmatyakul S, Thearmontree A. Partial pulpotomy on caries-free teeth using enamel matrix derivative or calcium hydroxide: a randomized controlled trial. Int Endod J 2009;42(7):584-92.

Leonardo MR, Barnett F, Debelian GJ, de Pontes Lima RK, Bezerra da Silva LA. Root canal adhesive filling in dogs' teeth with or without coronal restoration: a histopathological evaluation. J Endod 2007;33(11):1299-303.

Leonardo MR, Silva LAB, Leonardo RT, Utrilla LS, Assed S. Histological evaluation of therapy using a calcium hydroxide dressing for teeth with incompletely formed apices and periapical lesions. J Endod 1993;19:348-52.

Leonardo MR, Silva LAB, Leonardo RT. Devemos usar medicação intracanal no tratamento de dentes com necrose pulpar? In: Odontologia Integrada - Atualização multidisciplinar para o clínico e o especialista. Rio de Janeiro: Editora Pedro Primeiro Ltda; 1999. p.179-95.

Leonardo MR, Silva LAB, Utrilla LS, Assed S, Ether SS. Calcium hydroxide root canal sealers: histopathologic evaluation of apical and periapical repair after endodontic treatment. J Endod 1997;23:428-32.

Leonardo MR. Endodontia: tratamento de canais radiculares. Princípios técnicos e biológicos. São Paulo: Artes Médicas; 2005.

Lossdörfer S, Sun M, Götz W, Dard M, Jäger A. Enamel matrix derivative promotes human periodontal ligament cell differentiation and osteoprotegerin production in vitro. J Dent Res 2007;86(10):980-5.

Lyngstadaas SP, Lundberg E, Ekdahl H, Andersson C, Gestrelius S. Autocrine growth factors in human periodontal ligament cells cultured on enamel matrix derivative. J Clin Periodontol 2001;28(2):181-8. 
Markowitz K, Moynihan M, Liu M, Kim S. Biologic properties of eugenol and zinc-oxide eugenol. Oral Surg Oral Med Oral Pathol 1992;73:729-37.

Mellonig JT. Enamel matrix derivative for periodontal reconstructive surgery: technique and clinical and histologic case report. Int J Periodontics Restorative Dent $1999 ; 19(1): 8-19$.

Mestrener SR, Holland R, Dezan-Junior E. Influence of age on the behavior of dental pulp of dog teeth after capping with an adhesive system or calcium hydroxide. Dent Traumatol 2003;19:255-61.

Nagano T, Iwata T, Ogata Y, Tanabe T, Gomi K, Fukae M, Arai T, Oida S. Effect of heat treatment on bioactivities of enamel matrix derivatives in human periodontal ligament (HPDL) cells. J Periodontal Res 2004;39(4):249-56.

Nakamura Y, Hammarström L, Lundberg E, Ekdahl H, Matsumoto K, Gestrelius S, Lyngstadaas SP. Enamel matrix derivative promotes reparative processes in the dental pulp. Adv Dent Res 2001;15:105-7.

Nakamura Y, Hammarström L, Matsumoto K, Lyngstadaas SP. The induction of reparative dentine by enamel proteins. Int Endod J 2002;35(5):407-17.

Nakamura Y, Slaby I, Matsumoto K, Ritchie HH, Lyngstadaas SP. Immunohistochemical characterization of rapid dentin formation induced by enamel matrix derivative. Calcif Tissue Int 2004;75:243-52.

Narani N, Owen GR, Häkkinen L, Putnins E, Larjava H. Enamel matrix proteins bind to wound matrix proteins and regulate their cell-adhesive properties. Eur J Oral Sci 2007;115(4):288-95.

Nosrat IV, Nosrat CA. Reparative hard tissue formation following calcium hydroxide application after partial pulpotomy in cariously exposed pulps of permanent teeth. Int Endod J 1998;31:221-6. 
Oguntebi B, Clark A, Wilson J. Pulp capping with Bioglass ${ }^{\circledR}$ and autologous demineralized dentin in miniature swine. J Dent Res 1993;72:484-9.

Olsson H, Davies JR, Holst KE, Schröder U, Petersson K. Dental pulp capping: effect of Emdogain gel on experimentally exposed human pulps. Int Endod J 2005;38(3):18694.

Palioto DB, Coletta RD, Graner E, Joly JC, de Lima AF. The influence of enamel matrix derivative associated with insulin-like growth factor-I on periodontal ligament fibroblasts. J Periodontol 2004;75(4):498-504.

Papagerakis P, MacDougall M, Hotton D, Bailleul-Forestier I, Oboeuf M, Berdal A. Expression of amelogenin in odontoblasts. Bone 2003;32(3):228-40.

Parkar MH, Tonetti M. Gene expression profiles of periodontal ligament cells treated with enamel matrix proteins in vitro: analysis using cDNA arrays. J Periodontol 2004;75(11):1539-46.

Queiroz AM, Assed S, Leonardo MR, Nelson-Filho P, Silva LAB. MTA and calcium hydroxide for pulp capping. J Appl Oral Sci 2005;13:126-30.

Rangel SR, Leonardo MR, Silva LAB, Assed S, Nelson-Filho P. Evaluación clínica y radiográfica de dientes deciduos sometidos a la técnica de pulpotomia con hidroxido de calcio. Vida y Salud 1998;5:18-21.

Ranly DM, Garcia-Godoy F. Current and potential pulp therapies for primary and young permanent teeth. J Dent 2000;28:153-161.

Rasperini G, Ricci G, Silvestri M. Surgical technique for treatment of infrabony defects with enamel matrix derivative (Emdogain): 3 case reports. Int J Periodontics Restorative Dent 1999;19(6):578-87.

Rodrigues TL, Marchesan JT, Coletta RD, Novaes AB Jr, Grisi MF, Souza SL, Taba M Jr, Palioto DB. Effects of enamel matrix derivative and transforming growth factor-beta1 on human periodontal ligament fibroblasts. J Clin Periodontol 2007;34(6):514-22. 
Saito A, Hayakawa H, Ota K, Fujinami K, Nikaido M, Makiishi T. Treatment of periodontal defects with enamel matrix derivate: clinical evaluation at early healing stages. Bull Tokyo Dent Coll 2010;51(2):85-93.

Sarrami N, Pemberton MN, Thronhil MH, Theaker ED. Adverse reactions associated with the use of eugenol in Dentistry. Br Dent J 2002;193:257-9.

Schlueter SR, Carnes DL, Cochran DL. In vitro effects of enamel matrix derivative on microvascular cells. J Periodontol 2007;78(1):141-51.

Schröder U, Granath LE. Early reaction of intact human teeth to calcium hydroxide following experimental pulpotomy and its significance to the development of hard tissue barrier. Odont Revy 1971;22:379-96.

Schröder U. Effects of calcium hydroxide-containing-pulp-capping agents on pulp cell migration, proliferation and differentiation. J Dent Res 1985;64:541-8.

Schwartz Z, Carnes DL Jr, Pulliam R, Lohmann CH, Sylvia VL, Liu Y, Dean DD, Cochran $\mathrm{DL}$, Boyan BD. Porcine fetal enamel matrix derivative stimulates proliferation but not differentiation of pre-osteoblastic 2T9 cells, inhibits proliferation and stimulates differentiation of osteoblast-like MG63 cells, and increases proliferation and differentiation of normal human osteoblast NHOst cells. J Periodontol 2000;71(8):128796.

Sculean A, Donos N, Miliauskaite A, Arweiler N, Brecx M. Treatment of intrabony defects with enamel matrix proteins or bioabsorbable membranes. A 4-year follow-up split-mouth study. J Periodontol 2001;72(12):1695-701.

Sculean A, Schwarz F, Becker J, Brecx M. The application of an enamel matrix protein derivative (Emdogain) in regenerative periodontal therapy: a review. Med Princ Pract 2007;16(3):167-80.

Sculean A, Schwarz F, Chiantella GC, Arweiler NB, Becker J. Nine-year results following treatment of intrabony periodontal defects with an enamel matrix derivative: report of 26 cases. Int J Periodontics Restorative Dent 2007;27(3):221-9. 
Seux D, Couble ML, Hartmann JP, Gauther JP, Magloire H. Odontoblast-like cytodifferenciation of human dental pulp cells in vitro in the presence of a calcium hydroxide-containing cement. Arch Oral Biol 1991;36:117-28.

Silva FWGP. Resposta pulpar e periapical de dentes de cães após pulpotomia e utilização da proteína óssea morfogenética (rHuBMP-7). Estudo histopatológico e radiográfico [dissertação]. Ribeirão Preto: Faculdade de Odontologia de Ribeirão Preto da Universidade de São Paulo; 2006.

Silva LAB, Assed S, Silva FWGP. Rizogênese incompleta. In: Assed S. Odontopediatria: bases científicas para a prática clínica. Artes Médicas: São Paulo; 2005. p.741-68.

Silva LAB, de Paula e Silva FW, Leonardo MR, Assed S. Pulpal and periapical response of dogs' teeth after pulpotomy and use of recombinant human bone morphogenetic protein-7 as a capping agent. J Dent Child 2007;74(2):79-84.

Silva LAB, Freitas AC, Carvalho FK, Queiroz AM, Nelson-Filho P, Porto-Neto ST. Direct pulp capping with a self-etching adhesive system: histopathologic evaluation in dogs' teeth. Oral Surg Oral Med Oral Pathol Oral Radiol Endod 2009;108(1):e34-40.

Silva LAB, Leonardo MR, Faccioli LH, Figueredo F. Inflammatory response to calcium hydroxide based root canal sealers. J Endod 1997;23:86-90.

Silva LAB, Leonardo MR, Nelson-Filho P, Medeiros AS, Rossi MA. Pulp response of anionic lyophilized collagen matrix with or without hydroxyapatite after pulpotomy in dog's teeth. Mat Res 2006;9(2):175-180.

Silva LAB, Paula e Silva FW, Leonardo MR, Assed S. Radiographic evaluation of pulpal and periapical response of dogs' teeth after pulpotomy and use of recombinant human bone morphogenetic protein-7 as a capping agent. J Dent Child 2008;75(1):14-9.

Six N, Lasfargues JJ, Goldberg M. Differential repair responses in the coronal and radicular areas of the expased rat molar pulp induced by recombinant human bone morphogenetic protein 7 (osteogenic protein 1). Arch Oral Biol 2002;47:177-87. 
Song AM, Shu R, Xie YF, Song ZC, Li HY, Liu XF, Zhang XL. A study of enamel matrix proteins on differentiation of porcine bone marrow stromal cells into cementoblasts. Cell Prolif 2007;40(3):381-96.

Souza-Gugelmin MCM, Lima SNM, Lima CDL, Jacobovitz M, Ito IY. Biossegurança: controle de infecção na Odontologia. In: Leonardo MR. Endodontia: tratamento de canais radiculares: princípios técnicos e biológicos. São Paulo: Artes Médicas; 2005. p.365-406.

Spahr A, Lyngstadaas SP, Slaby I, Haller B, Boeckh C, Tsoulfidou F, Hammarström L. Expression of amelin and trauma-induced dentin formation. Clin Oral Investig 2002;6(1):51-7.

Sübay RK, Asci S. Human pulp response to hydroxyapatite and a calcium hydroxide material as direct capping agents. Oral Med Oral Pathol 1993;80:330-7.

Ten Cate AR. The role of epithelium in the development, structure and function of the tissues of tooth support. Oral Dis 1996;2(1):55-62.

Venezia E, Goldstein M, Boyan BD, Schwartz Z. The use of enamel matrix derivative in the treatment of periodontal defects: a literature review and meta-analysis. Crit Rev Oral Biol Med 2004;15(6):382-402.

Watts A, Paterson RC. Pulpal response to a zinc oxide-eugenol cement. Int Endod J $1987 ; 20: 82-6$. 
ANEXo 



\section{UNIVERSIDADE DE SÃO PAULO \\ Campus de Ribeirão Preto}

Comissão de Ética no Uso de Animais

\section{E R T I F I C A D O}

Certificamos que o trabalho (Protocolo $n^{\circ}$ 08.1.87.53.9), intitulado: "Resposta Pulpar e Periapical de Dentes de Cães Após Pulpotomia e Utilização de Derivado da Matriz do Esmalte. Estudo microscópio e radiográfico", de autoria de Lourdes Yanissely Garcia Olmedo e de Léa Assed Bezerra da Silva, por estar de acordo com os Princípios Éticos na Experimentação Animal adotado pela Comissão de Ética no Uso de Animais (CEUA) do Campus de Ribeirão Preto - USP foi aprovado em reunião da CEUA de 08.04.2008.

Ribeirão Preto, 14 de abril de 2008

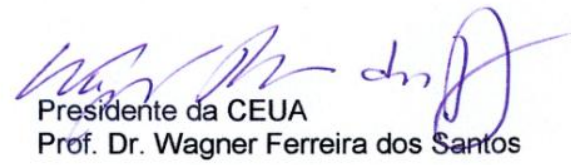

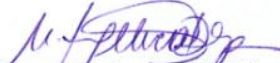

Secretária da CEUA

Maria Angélica Depiro

Av. Bandeirantes, 3900 - CEP 14040-900 - Ribeirão Preto - São Paulo Fone: (16) 36024469 - Fax: (16) 36337964 